\title{
Overlapping sea level time series measured using different technologies: an example from the REDMAR Spanish network
}

\author{
B. Pérez ${ }^{1}$, A. Payo ${ }^{2, *}$, D. López ${ }^{2}$, P. L. Woodworth ${ }^{3}$, and E. Alvarez Fanjul ${ }^{1}$ \\ ${ }^{1}$ Puertos del Estado, Madrid, Spain \\ ${ }^{2}$ SIDMAR Bernhard Pack S.L., Benissa, Alicante, Spain \\ ${ }^{3}$ National Oceanography Centre, Liverpool, UK \\ * now at: Environmental Change Institute, University of Oxford, UK
}

Correspondence to: B. Pérez (bego@ puertos.es)

Received: 19 December 2012 - Published in Nat. Hazards Earth Syst. Sci. Discuss.: -

Revised: 26 September 2013 - Accepted: 13 October 2013 - Published: 13 March 2014

\begin{abstract}
This paper addresses the problems of overlapping sea level time series measured using different technologies and sometimes from different locations inside a harbour. The renovation of the Spanish REDMAR (RED de MAReógrafos) sea level network is taken here as an example of the difficulties encountered: up to seventeen old tide gauge stations have been replaced by radar tide gauges all around the Spanish coast, in order to fulfil the new international requirements on tsunami detection. Overlapping periods between old and new stations have allowed the comparison of records in different frequency ranges and the determination of the impact of this change of instrumentation on the long-term sea level products such as tides, surges and mean sea levels. The differences encountered are generally within the values expected, taking into account the characteristics of the different sensors, the different sampling strategies and sometimes the different locations inside the harbours. However, our analysis has also revealed in some cases the presence of significant scale errors that, overlapping with datum differences and uncertainties, as well as with hardware problems in many new radar gauges, may hinder the generation of coherent and continuous sea level time series. Comparisons with nearby stations have been combined with comparisons with altimetry time series close to each station in order to better determine the sources of error and to guarantee the precise relationships between the sea level time series from the old and the new tide gauges.
\end{abstract}

\section{Introduction}

The REDMAR (RED de MAReógrafos) sea level network was established by the Spanish Harbour Authorities in 1992. It was originally based on 13 acoustic tide gauges (SRD) and enlarged later with 4 additional stations based on AANDERAA (AAND) pressure sensors (Pérez and Rodríguez, 1994; Pérez and López Maldonado, 2003). In 2001-2002 the SRD maker stopped manufacturing the models used by REDMAR, which obliged the Spanish Harbour Authorities to look for a new sensor to renovate and continue the operation of the network. Since that moment, two additional important factors have influenced the decisions taken for the renovation. One factor was that new radar-based technologies became available that were reported to be more reliable and precise than acoustic and pressure sensors. The second was that in 2003 a small tsunami impacted the Balearic Islands (Alasset et al., 2006; Alvarez-Gómez et al., 2010) and was underestimated by the standard 5 min sampling of the existing tide gauges. More rapid sampling was considered an important requirement for monitoring future tsunami events.

The renovation was then focused on the study of radar technology and the upgrade of the technical requirements of sea level sensors for dealing with other higher frequency phenomena such as tsunamis and "seiches". The latter was of course reinforced by the effect of the dramatic tsunami of 2004 in the Indian Ocean, which has extended progressively this idea to all the sea level networks in the world (UNESCO, 2007). 


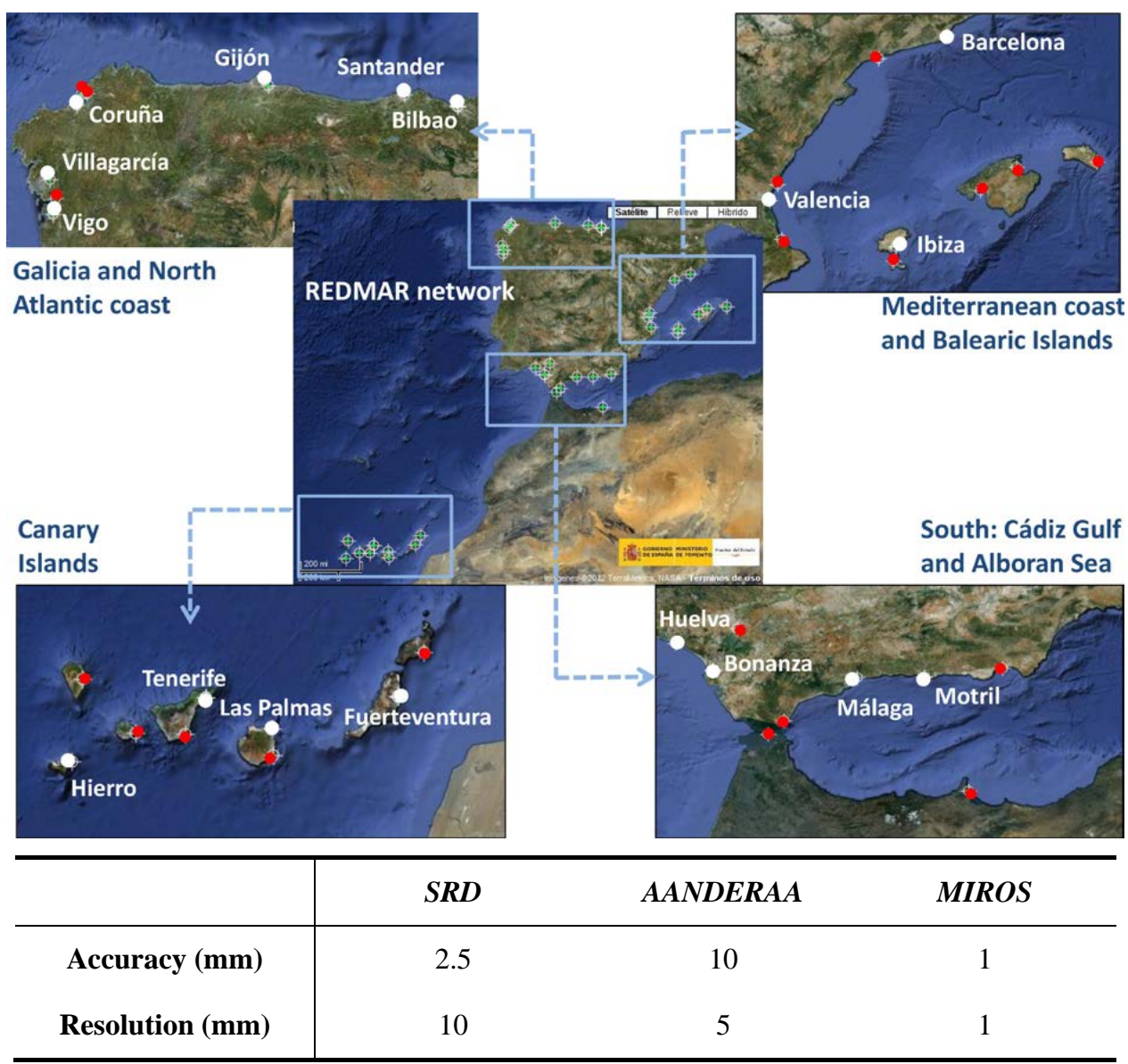

Fig. 1. REDMAR sea level network in 2012: 35 MIROS stations and 2 AANDERAA pressure sensors in the Canary Islands. Detailed maps show by solid white circles the positions of the older tide gauges (SRD or AANDERAA) that were renovated or upgraded with MIROS radar gauges. The remaining points shown by solid red circles are completely new stations established between 2006 and 2012 . The attached table includes the accuracy and resolution of each of the sensors, claimed by the manufacturers, assuming a $5 \mathrm{~m}$ tidal range and $1 \mathrm{~min}$ averages.

In 2002 a pilot station was established in Vilagarcía harbour, on the northwest coast of Spain, for testing up to eight different acoustic, radar and pressure sensors (Martín Míguez et al., 2005). After more than one year of simultaneous measurements, the MIROS (MIcrowave Remote sensor for the Ocean Surface) FMCW (frequency modulated continuous wave) radar sensor was selected based on the following criteria:

- High-precision of the individual measurements and selectable data sampling (1 min or less);

- $2 \mathrm{~Hz}$ original raw data sampling that allowed wind wave or agitation (short waves inside the harbour) parameters to be estimated (needed in some harbours);

- Good performance and stability of the datum;

- Good communication with the manufacturer for implementation of additional requirements of Puertos del
Estado for the REDMAR network: data formats, GPS (Global Positioning System) time control, etc.

MIROS radar sensors use an FMCW system in which transmitted radar waves are mixed with signals reflected from the surface to determine the phase shift between them and thereby the range (Woodworth and Smith, 2003; Martín Míguez et al., 2005). Between 2007 and 2011, practically all the REDMAR tide gauge stations were upgraded to incorporate a MIROS radar sensor. At the same time, many new harbours have been incorporated into the network, including this new equipment. The network is nowadays composed of 35 multipurpose radar stations which allow the measurement of the whole range of frequencies of sea level variation and two AANDERAA pressure sensors (Pérez et al., 2008). The spatial coverage has been significantly improved in the Canary and the Balearic Islands (one or two tide gauges available now for each island), as well as on the Mediterranean mainland Spanish coast, the Gibraltar Strait 
and Melilla (North Africa) (Fig. 1). Most of the new stations are particularly important for tsunami monitoring purposes in the European/Mediterranean region, although their installation is meant to satisfy also all other possible applications.

Monthly mean sea levels of the REDMAR network are provided annually to the Permanent Service for Mean Sea Level (PSMSL, www.psmsl.org) and the data are used by scientists all around the world. For this reason one of the main concerns during this process of renovation was to guarantee the continuity of the longer time series of sea level. Taking this into account, most of the new stations overlapped during at least one year with the old stations (solid white circles in Fig. 1), following the recommendation of the Global Sea Level Observing System (IOC, 2006), except at Coruña station, where a sudden malfunction of the SRD sensor with no spare parts available reduced the overlapping period to just 10 months, and at Valencia, where harbour development forced the dismantling of the old station after just 4 months.

The process of comparison has been performed for $5 \mathrm{~min}$, hourly, daily and monthly values, in order to account for the different sea level processes. Comparisons also include the main harmonic constants and the residual component (observations - tide). Some of the new tide gauges are at exactly the same location as the old tide gauge, making datum connection easier; in these cases the expected differences at all frequencies should be small. However, when the new tide gauge has been installed at another location in the harbour with different agitation/high frequency variability, only the lower frequencies of sea level are expected to be coherent with the old station, and a high precision levelling is needed to connect both tide gauges to the same datum.

As the adequacy of the MIROS radar sensor was assessed in previous experiments, such as the one in Vilagarcía (Martín Míguez et al., 2005), the objective of this study is focused on the scientific impact of the technological renovation of the network, assessed by identifying the differences in the sea level signals and their influence on the different products such as the long-term time series provided to the PSMSL. Decisions about correcting the data, or providing information as metadata if necessary, will result from this study. It is not intended here to make a comprehensive analysis of all possible sources of error at each station, but special emphasis has been placed on the datum connection between stations, the scale errors that generate a bias in the data and the influence of a delamination problem detected in the radar sensors, as these may affect the long-term trends in mean sea levels. For this, use of altimetry data has allowed a better determination of the impact of the network renovation in the monthly means. A detailed review of these differences should also be taken into account for extreme analysis studies (not included in this paper), historical evolution of tides and tidal ranges, etc.
The paper is structured as follows: the second section presents a review of the main sources of error, general or specific to REDMAR, that can result in differences between two simultaneous tide gauge data sets from the same harbour; the third section will describe the data employed and the methodology for data comparison during REDMAR renovation; and the fourth section will present the results and discussion of this comparison exercise as well as the impact of the network renovation on the main sea level products.

\section{Sources of error and differences between two tide gauges}

There are many technical and environmental/oceanographic factors that can result in differences between tide gauge data sets in a comparison exercise (Lennon, 1967; Shih and Porter, 1981; Lentz, 1993): geophysical peculiarities of the tide gauge location such as harbour resonances, wind or wave setup, biofouling in the orifice of tubes or wells, different response to sea level oscillations inside a tube or well, influence of currents (Bernoulli effect), density differences that affect especially the pressure sensors, different sensitivities of the sensors to the tidal range, datum changes and drifts, different sampling strategy, shifts in the clock system, etc. It is necessary to have in mind all these potential problems in order to extract correct conclusions about the adequate performance of a sensor, something that becomes even more difficult for a whole network of stations with diverse installations and meteorological and environmental conditions. In this particular study, it should be stressed that the new MIROS REDMAR stations measure sea level without a protective tube, in contrast to the old stations, in order to also provide local wind wave data. A detailed study of the influence of high sea state in the water level quality remains to be done for each individual harbour and will not be included in this paper. However, the errors introduced by this fact will certainly contribute to and be a part of the errors and differences found in this comparison.

A sudden malfunction of a sensor can occur at any time during the overlapping period, both in the old and the new tide gauge. During the renovation period of the REDMAR network, several problems appeared in some of the MIROS radar sensors that had not occurred before, delaying the final comparison of data and its interpretation. The experience has resulted in the detection of a set of antennas with hardware problems (delamination). These antennas have been replaced by the manufacturer with new models with an improved design. A new procedure of checking and control of the operation of the antennas is now done remotely and they are also calibrated in a different and more precise way before installation, both by the manufacturer and at the maintenance company headquarters (more information can be obtained from the MIROS and SIDMAR companies, respectively). Of course, problems were also present in the old stations and this has been taken into account for the final interpretation of data. 


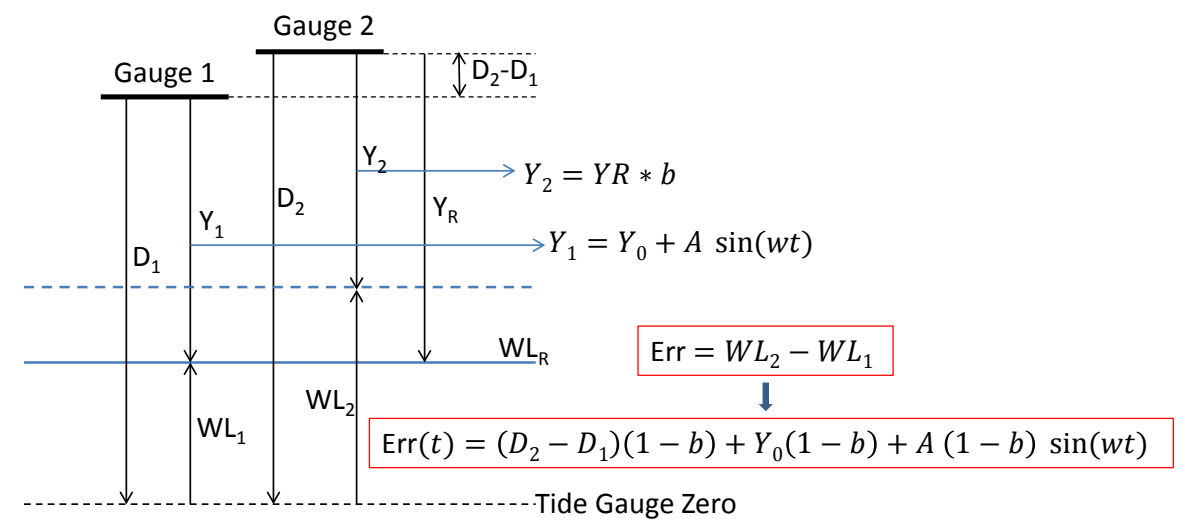

Fig. 2. Scheme used to explain how the presence of a scale error $(b \neq 1)$ in a water level time series $\left(\mathrm{WL}_{2}\right)$ introduces an additional term in the bias or mean difference between the time series and the real or reference time series $\left(\mathrm{WL}_{1}\right)$. In the example, the datum difference $\left(D_{2}-D_{1}\right)$ is assumed to be due to the sensor position, but it could be also due to different tide gauge zero or to a combination of both. Err $(t)$ is the error or difference between the two time series, composed of a constant term and a variable term (sinusoidal variation as the typical tide, for example). This constant term is related to the bias and varies with the datum difference, the scale error $b$ and the set-up of the station $Y_{0}$ (distance of the sensor to mean sea level).

As mentioned at the beginning of this section, there are two main types of sources of error: (a) those due to instrumental/installation problems, and (b) those due to physical and environmental influences. The former may sometimes be corrected so we will describe next some of them and their influence on the sea level data during the renovation of the REDMAR network.

\subsection{The scale error influence}

One common source of error when measuring sea levels is related to tide gauges systematically measuring sea levels different to the real ones by a factor $\varepsilon$ (the so-called scaleerror), with differences increasing with the distance to the sensor. When comparing with other sensors, this can be seen as a trend on the Van de Casteele plot (Lennon, 1968; IOC, 1985; Martín Míguez et al., 2008), and quantified from the slope of the linear fit between the two time series of sea levels as $\varepsilon=(b-1) \times 100$, with $b$ being the slope of the linear fit.

Although radar sensors may of course have their own scale error, it has been proved that this is much lower than the one from acoustic or pressure sensors. In the test station in Vilagarcía (Martín Míguez et al., 2005), the values of scale error were less than $0.1 \%$ between the MIROS radar and two different acoustic sensors, an Aquatrak loaned by NOAA (National Oceanic and Atmospheric Administration, US) and the SRD one from the REDMAR network.

A scale error in a sea level time series introduces a bias with respect to the original time series. This is easy to show, for example, if we consider a reference time series of sensor to water distance as $y_{1}=y_{0}+A \sin (t / T)$, where $t$ is time, and a second time series, $y_{2}=b * y_{1}$, affected by a scale error determined by $b$. If $y_{0}=300$ and $A=200$, for example, this roughly corresponds to a set-up similar to existing stations in the north of Spain, where the sensor is located around $300 \mathrm{~cm}$ above the maximum tide level and the tidal amplitude is $200 \mathrm{~cm}$ ( $T$ is chosen to be equal to $M_{2}$ period: $12.47 \mathrm{~h}$ ). If these two time series are converted to water level, $\mathrm{WL}_{i}$, by differences between each datum to the measured distances, (in our example we can use $D_{1}=399 \mathrm{~cm}, D_{2}=400 \mathrm{~cm}$, and a scale error of $2 \%$, i.e. $b=1.02$ ) the bias between the two time series $\mathrm{WL}_{2}$ and $\mathrm{WL}_{1}$ becomes $-5.98 \mathrm{~cm}$, which does not match the datum difference $\left(D_{2}-D_{1}=1.0 \mathrm{~cm}\right)$. This is so because the bias between two time series will depend not only on datum differences but also on the scale error, the nominal distances of the sensors above mean sea level measured at station set-up, and on the tidal range (this can be confirmed for the mentioned example by the exact expression of the error $\mathrm{WL}_{2}-\mathrm{WL}_{1}$, which can be easily obtained following the scheme in Fig. 2). In summary, in order to match the mean level of two different time series of sea level measured at the same location, but where a scale error might be present, an estimation of such scale error and understanding its influence in the bias is needed.

\subsection{Time shifts}

Another source of error is the time shift due to clock malfunction. This was a common error present in old tide gauges but not in the modern ones, such as the new stations of REDMAR, as they include a GPS receiver for time assignment, one of the main requirements of the new MIROS-based stations. The detection of this problem is easy and is reflected in an increased standard deviation of the differences (Stdv).

In order to have an idea of the influence of the time shifts in the comparison, two time series, one from the Atlantic coast (Bilbao) and another from the Mediterranean coast (Ibiza, 
Table 1. Statistics of differences (in $\mathrm{cm}$ ) between original and 2 min shifted time series for Bilbao and Ibiza (one month of data). Results are presented both for 1 min time series and for filtered hourly values. An additional computation is made for a few days with important "seiches" in Ibiza (last column).

\begin{tabular}{lrrcrr}
\hline & \multicolumn{2}{c}{ Bilbao } & \multicolumn{2}{c}{ Ibiza } & Ibiza (seiche period) \\
& 1 min data & Hourly data & 1 min data & Hourly data & 1 min data \\
\hline Mean: & -0.0098 & -0.0024 & -0.00008 & -0.0002 & -0.0004 \\
Max: & 6.90 & 4.10 & 6.50 & 0.30 & 6.20 \\
Min & -8.50 & -3.80 & -5.00 & -0.20 & -5.00 \\
Stdv: & 1.95 & 1.81 & 0.80 & 0.07 & 1.57 \\
\hline
\end{tabular}

Balearic Islands) were artificially delayed by 2 min. The experiment was made for one month of $1 \mathrm{~min}$ data in both cases. Differences between the original time series and the delayed one were then analysed and basic statistics computed, both for the original $1 \mathrm{~min}$ data and for the filtered hourly values (Table 1).

The table shows that a standard deviation of up to $1.8 \mathrm{~cm}$ for hourly values can be explained by just a 2 min shift at Bilbao, where the maximum tidal range is around $5 \mathrm{~m}$. However, at Ibiza, where there is a tidal range less than $20 \mathrm{~cm}$, the same time shift would produce an increase of only $0.07 \mathrm{~cm}$ in the standard deviation for hourly values. While the estimated errors relative to the tidal range are similar $(1.8 / 500 \approx$ $0.07 / 20 \approx 0.0035$ ), the observed increase of $0.07 \mathrm{~cm}$ at Ibiza is one order of magnitude less than the uncertainty on water level datum differences and therefore well within the expected uncertainty range $O(1 \mathrm{~cm})$ (see section about uncertainty on water elevation relation to datum). Larger values of Stdv will be obtained from 1 min time series differences in Ibiza and other Mediterranean stations with small tidal range during periods with larger "seiches" and resonance effects (right column of Table 1). Filtering to hourly values during these events significantly reduces the standard deviation of the differences (from 1.57 to $0.10 \mathrm{~cm}$ in the example).

Time shifts will be reflected of course in differences in the phases of the main harmonic tidal constituents. The presence of a clock malfunction will be evident if the stations are at the same location and more difficult to determine if there is some delay in the tide due to a different position or because of a lag stemming from the particular instrumentation (e.g. a blocked well in a conventional gauge). However, this error does not generate a bias so it is not so important for long-term mean sea level studies.

\subsection{Datum changes and drifts}

Datum or reference connection between the tide gauges is one of the basic and critical steps for a successful renovation of a sea level station. Unfortunately, other errors may mask this connection, such as the scale error mentioned above. High precision levelling between the contact points of the two sensors is needed, something that would require more expense and time if they are not at the same location. The bias or mean difference between the two water level time series should be practically zero once other sources of error such as the scale error have been eliminated. A trend in these differences will indicate the presence of a drift in one of the gauge datums, something very important for study of lower frequency climate or geological processes (secular trends), if this drift would be unnoticed and uncorrected for a period much longer than a year.

\subsection{Effective density effects in pressure sensors}

Pressure sensors, placed in the water below the lower low water mark, measure the hydrostatic pressure above them, requiring the estimation of the density of the seawater prior to the calculation of the sea level from the pressure measurement. In the particular case of the REDMAR pressure sensors (AAND), the influence of barometric pressure is compensated for by applying air pressure to one side of the transducer through an air pipe and compensating unit. The AAND sensors operate with a predefined constant value of density, determined during the installation phase for each station. This means that there is a potential influence of density variations on the derived sea level data.

The good performance of the AAND pressure sensors will then depend on the temporal variability of the temperature and the salinity, which we do not always know. One factor could be if density varies seasonally because, for example, the gauges are located close to the mouth of a river which has seasonally varying runoff. Let us take as an example the conditions of the pressure sensor installed at Ibiza station, located at $2 \mathrm{~m}$ depth and with a tidal signal of $10 \mathrm{~cm}$ range: if we consider a seasonal variation of water density of $\pm 5 \mathrm{~kg} \mathrm{~m}^{-3}$, this would be reflected in a sea level seasonal signal of $\pm 1.5 \mathrm{~cm}$. As will be shown later, this could explain the differences encountered at Ibiza during the renovation (this seasonal variation is practically negligible, however, in the other AAND sensors of the REDMAR network). Of course if the sensor is located deeper, the sea level error would be larger for the same density variations. 


\subsection{Air temperature effects in acoustic sensors}

Acoustic sensors, located a few metres above the water surface, measure the travel time of acoustic pulses reflected vertically from the air/sea interface to derive the distance to the water surface and then the sea level height relative to a datum. This travel time depends on the determination of the speed of sound, which varies with the air conditions, especially with temperature gradients. In principle, the speed of sound is estimated in the SRD sensors before each measurement, using a calibration measurement over the first $1 \mathrm{~m}$ of range from the sensor. However, the sea level measurement itself requires knowing the speed of sound over the full range, and this value may not correspond well to the calibrated one. The sensors measure inside protective tubes painted white to avoid temperature gradients along the tube in larger tidal regimes. Errors in their operation will be reflected in an increased scale error and lower precision of the sensor during low waters compared to during high waters. On the other hand, the temperature gradients will vary throughout the year, leading to seasonal variations of the scale error that may become evident when comparing the acoustic sensors with radar sensor data (as a seasonal signal in the mean sea levels differences).

\subsection{Delamination problem in radar antennas}

One of the main problems in the comparison of old and new tide gauges in the REDMAR network became apparent after a detailed study of sea level data at Algeciras harbour (Gibraltar Strait), in May 2010. This new station, based on a MIROS radar sensor, was installed in the summer of 2009. Real-time quality control procedures at that time showed an apparently good performance of the antenna. However, when data from the Spanish Institute of Oceanography in Algeciras Bay and from the National Oceanography Centre Liverpool tide gauge at Gibraltar were compared with the MIROS sensor, an apparent slow rise of mean sea level during several hours became evident in the MIROS data with respect to the other two tide gauges. After that, the mean sea level relative to these sensors became stable and remained a few centimetres above the original signal. Figure 3 shows the effect of delamination on the daily means at Algeciras and its correction after replacing the antenna in July 2010.

An inspection of the MIROS installation at Algeciras revealed the existence of a problem in the MIROS antenna. After contacting the manufacturer we were informed that this was a potential problem of a set of antennas provided to REDMAR, basically consisting of a failure in the glue joint of the two circuit boards that form the antenna, allowing air to enter inside the joint and thus starting a delamination process.

As a consequence of this, an immediate plan of verification and substitution of all the installed MIROS radar sensors was put in place in collaboration with the maintenance company and the manufacturer. At the same time, new calibration and

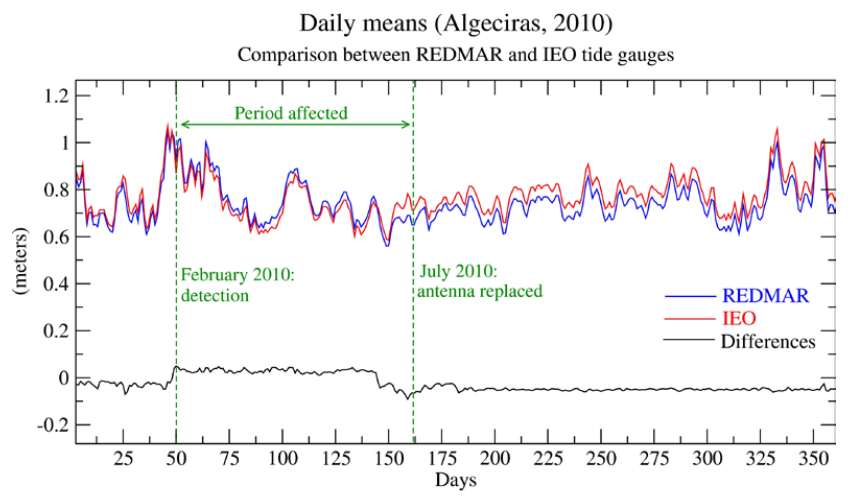

Fig. 3. Influence of delamination in daily mean sea levels at Algeciras harbour. Daily means from the REDMAR MIROS station (blue) are lower than the daily means from IEO tide gauge (red) due to their datum difference. During the period the MIROS antenna was delaminated (shown by the green arrow) mean sea levels from REDMAR became higher. The problem disappeared after MIROS antenna replacement in July 2010, when the IEO sea levels became higher again (and the difference constant). The effect is clear in the differences time series (black line).

real-time monitoring procedures were established for these sensors to avoid a potential repetition of the problem. Up to 11 of the 17 antennas of the MIROS devices that were installed to replace the older tide gauges have shown evidence of delamination with different degrees of impact on the data (Fig. 4, red periods show data affected by delamination). All the REDMAR MIROS stations have been replaced at the time of writing of this paper, independently of the detection of delamination problems, following the manufacturer's advice.

\section{Data and methods}

\subsection{Stations and data description}

Seventeen pairs of tide gauges stations are used (Fig. 1 and Table 2), four of them based on pressure sensors (AAND) and the rest on acoustic (SRD) sensors. The location of the new radar station might be at the same or at a different location inside the harbour, the latter sometimes unavoidable due to harbour works and development (e.g. Valencia and Barcelona). Other times, the reason for relocation was more related to the interest of monitoring higher frequency phenomena such as agitation (Vigo, Málaga or Motril stations). Available periods of overlap for comparison range from 120 days to more than three years, although just the segment where both stations were working properly is used (Fig. 4).

Table 2 presents some basic information about the diverse conditions of the upgraded stations in REDMAR: overlapping period, relative position and short names employed for old and new sensors as well as information about problems encountered. 


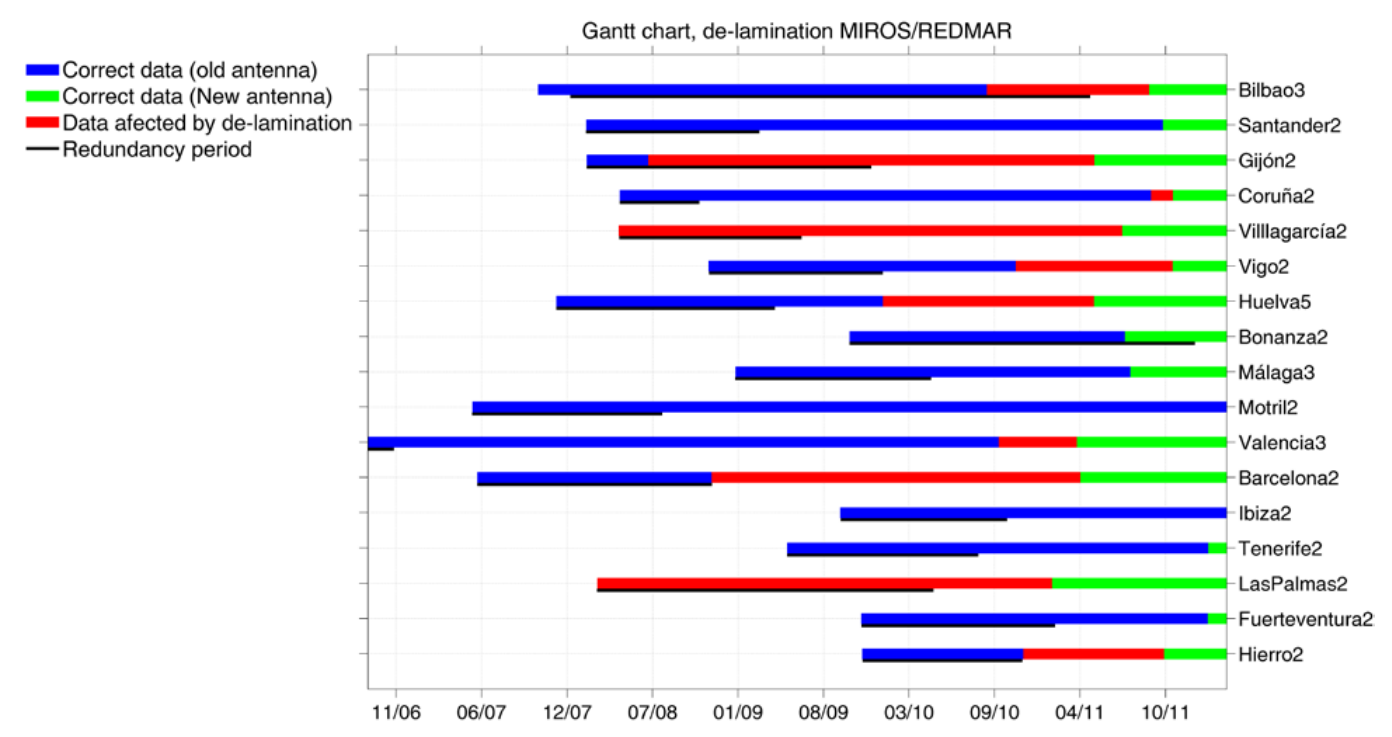

Fig. 4. Gantt chart showing the period of operation of the MIROS radar sensors installed to replace an old REDMAR station (black line is the overlapping period with the old sensor). Red: period of data affected by the delamination problem in the new sensors. Blue: data not affected by delamination. As can be seen red periods do not always coincide with the overlapping period. All the stations now have the new model of antenna (green: Motril and Ibiza replaced in 2012).

Raw data consist of 1 min averages for MIROS radar sensors and of $5 \mathrm{~min}$ data for the AAND and SRD sensors. The 1 min radar data were averaged to 5 min sampling in order to make the comparisons with the older tide gauges. However, it is important to take into account that the SRD 5 min value corresponds to a mean of around $40 \mathrm{~s}$ of multiple echoes within the $5 \mathrm{~min}$, and that the AAND $5 \mathrm{~min}$ value corresponds to the average of last 5 min of $1 \mathrm{~s}$ measurements. Use of subsampling instead of a 5 min average has been tried in the radar data (not possible for the older ones) for two of the stations, Huelva (SRD sensor and large tidal range) and Ibiza (AAND sensor and very small tidal range), but no important differences in the statistical results of the comparisons have been found. The MIROS strategy will be the one adopted in the future, so it seems reasonable to look for differences in the overall final products without considering the subsampling.

After detailed quality control, the data used for this study are some of the products generated by Puertos del Estado on a regular basis for all the tide gauges of the Spanish REDMAR network: the $5 \mathrm{~min}$ (minimum standard data sampling of the old tide gauges), hourly, daily and monthly averaged sea level time series. We will focus then on the coherence of processes with frequencies lower than 0.1 cycles $\mathrm{min}^{-1}$. Detailed tide gauge benchmark information was used to analyse the differences observed between time series concerning datum connection.

\subsection{Comparison method}

The first step consists of the visualization of the time series of the differences (Fig. 5), and the computation of the following basic statistical descriptors: bias or mean difference, standard deviation (Stdv), $50 \%$ percentile $\left(p_{50}\right)$, maximum and minimum difference $\left(R_{\max }, R_{\min }\right)$ and Pearson's correlation coefficient, $R$. For the hourly and daily time series, and for the same time period, the linear trend is also computed, and the slope given with its $68 \%$ confidence interval $( \pm$ one standard deviation).

A linear fit, $y=a+b x$, between the two time series is calculated to estimate the scale error from the slope of the linear fit as $\varepsilon=(b-1) \times 100$. The Van de Casteele plots for the $5 \mathrm{~min}$, hourly, daily and monthly averages are then obtained. These should present a tilt or inclination for $5 \mathrm{~min}$ and hourly values if the scale error value is related to differences in the tidal range. If the scale error in the old time series is corrected, this inclination disappears. In other cases, the inclination is not present, indicating a different origin of the scale error or the inclination appears in the daily and monthly means instead due to seasonal variations.

The time shift between the two 5 min time series was estimated in order to quantify possible loss of synchrony between station clocks in the following way: the power crossspectra of the differences is calculated using the Welch method (Welch, 1967). The phase at a particular frequency, $\theta(f)$, can then be converted to time shift as $\Delta t(f)=$ $\theta(f) / 2 \pi f$. We chose the frequency of the $M_{2}$ tidal constituent (period $12.47 \mathrm{~h}$ ) that corresponds with the dominant peak of the cross-spectra for most of the stations (especially 
Table 2. Stations upgraded within the REDMAR network, including relative positions of the old and new tide gauges (on the same or on another quay of the harbour), type of old sensor, redundancy period for the comparison studies and main problems from the new and old sensors (delamination in the MIROS antennas or malfunction of the old sensor).

\begin{tabular}{llllclll}
\hline & Location & Type & $\begin{array}{l}\text { Old/New } \\
\text { short names }\end{array}$ & $\begin{array}{c}\text { Overlapping } \\
\text { period }\end{array}$ & (days) & $\begin{array}{l}\text { Delamination } \\
\text { MIROS }\end{array}$ & $\begin{array}{l}\text { Malfunction } \\
\text { old sensor }\end{array}$ \\
\hline Bilbao & Different & SRD & Bilb/Bil3 & $20090603-20100112$ & 1189 & Yes & No \\
Santander & Same & SRD & Sant/San2 & $20080206-20090317$ & 397 & No & No \\
Gijón & Same & SRD & Gijo/Gij2 & $20080208-20080701$ & 323 & Yes & No \\
Coruña & Same & SRD & Coru/Cor2 & $20080425-20081028$ & 184 & No & Yes \\
Villagarcía & Different & SRD & Vill/Vil2 & $20080424-20090624$ & 423 & Yes & No \\
Vigo & Different & SRD & Vigo/Vig2 & $20081120-20091231$ & 358 & No & No \\
Huelva & Same & SRD & Huel/Hue5 & $20080101-20081231$ & 361 & No & No \\
Bonanza & Same & SRD & Bona/Bon2 & $20100113-20101113$ & 487 & No & Yes \\
Málaga & Different & SRD & Mala/Mal3 & $20090122-20100423$ & 411 & No & No \\
Motril & Different & AAND & Motr/Mot2 & $20070922-20080802$ & 208 & No & Yes \\
Valencia & Different & SRD & Vale/Val3 & $20060801-20061114$ & 120 & No & Yes \\
Barcelona & Different & SRD & Barc/Bar2 & $20071231-20081030$ & 310 & No & No \\
Ibiza & Same & AAND & Ibiz/Ibi2 & $20090924-20101018$ & 374 & No & Yes \\
Tenerife & Same & SRD & Tene/Ten2 & $20090522-20100812$ & 427 & No & Yes \\
Las Palmas & Different & SRD & LasP/Las2 & $20090101-20100429$ & 766 & Yes & No \\
Fuerteventura & Different & AAND & Fuer/Fue2 & $20091112-20110207$ & 357 & No & No \\
Hierro & Different & AAND & Hier/Hie2 & $20091114-20100615$ & 361 & No & Yes \\
\hline
\end{tabular}

the ones in the Atlantic coast). Notice that the entire time series is used for this computation even though the clocks of pressure and acoustic sensors were checked and synchronized every three months during in situ maintenance. This method was used as a first approximation of the time shift and was later compared with the observed values of this time shift during maintenance.

\subsubsection{Uncertainty on water level relation to a datum}

Knowing the uncertainty associated to the sea level measured by each type of sensor is key for analysing the overlapping time series. This uncertainty will depend not only on the type of instrument but also on the procedure followed to convert raw measurements to water level relative to a datum. Figure 6 shows a general scheme to convert distance measurement to water level relative to a datum, in the case of acoustic and radar sensors located above the water surface. According to this, datum definition will have its own uncertainties that will stem from, among other sources, the ability of the field technician to adjust the datum (not lower than $1 \mathrm{~cm}$ ), the levelling error between the tide gauge bench mark (TGBM) and the sensor contact point (which is $0.03 \mathrm{~cm}$ for the REDMAR network), the repeatability of measurements (depending on the sensor) and the variability of environmental conditions. Taking all these sources of error into account and using the propagation error theory, we have calculated a total uncertainty of the datum definition of $0.15 \mathrm{~cm}$ for the MIROS radar sensor, $1.012 \mathrm{~cm}$ for the acoustic SRD sensor and $1.41 \mathrm{~cm}$ for the AANDERAA pressure sensor.
From the discussion above and, provided no other sources of error or malfunction are present, datum determination will be more precise for the MIROS stations than for the older tide gauges in REDMAR. This will also imply that bias differences below $1.4 \mathrm{~cm}$ in the case of AAND sensors and below $1.0 \mathrm{~cm}$ in the SRD sensors will be within this uncertainty.

\subsubsection{Tide and surge comparison}

A change of instrumentation may also affect the tidal harmonic constants and the meteorological residuals in a tidal analysis computation, two basic products from a tide gauge station. One of the critical functions of the REDMAR network, as for other sea level networks in the world, is the computation of the astronomical tide at each harbour and thereby the prediction of future tidal levels. No less important is also the use of tide gauge data for validation of storm surge forecasts. For the latter, a meteorological residual time series is computed by subtracting the tide from the observations. In Puertos del Estado this validation is performed in near-real time (each $12 \mathrm{~h}$ ) within the NIVMAR Sea Level Forecast System (Alvarez Fanjul et al., 2001), and a simple scheme of post-processing is used to correct the meteorological sea level forecast provided by a numerical model, by comparison with the residual time series obtained from each tide gauge for the last few days.

In order to compare these products, it is important to use exactly the same period of time, as this affects the tidal constituents. Thus, a harmonic analysis was performed for the redundancy period at each pair of stations, and the residual component was obtained using these harmonic constants. As 

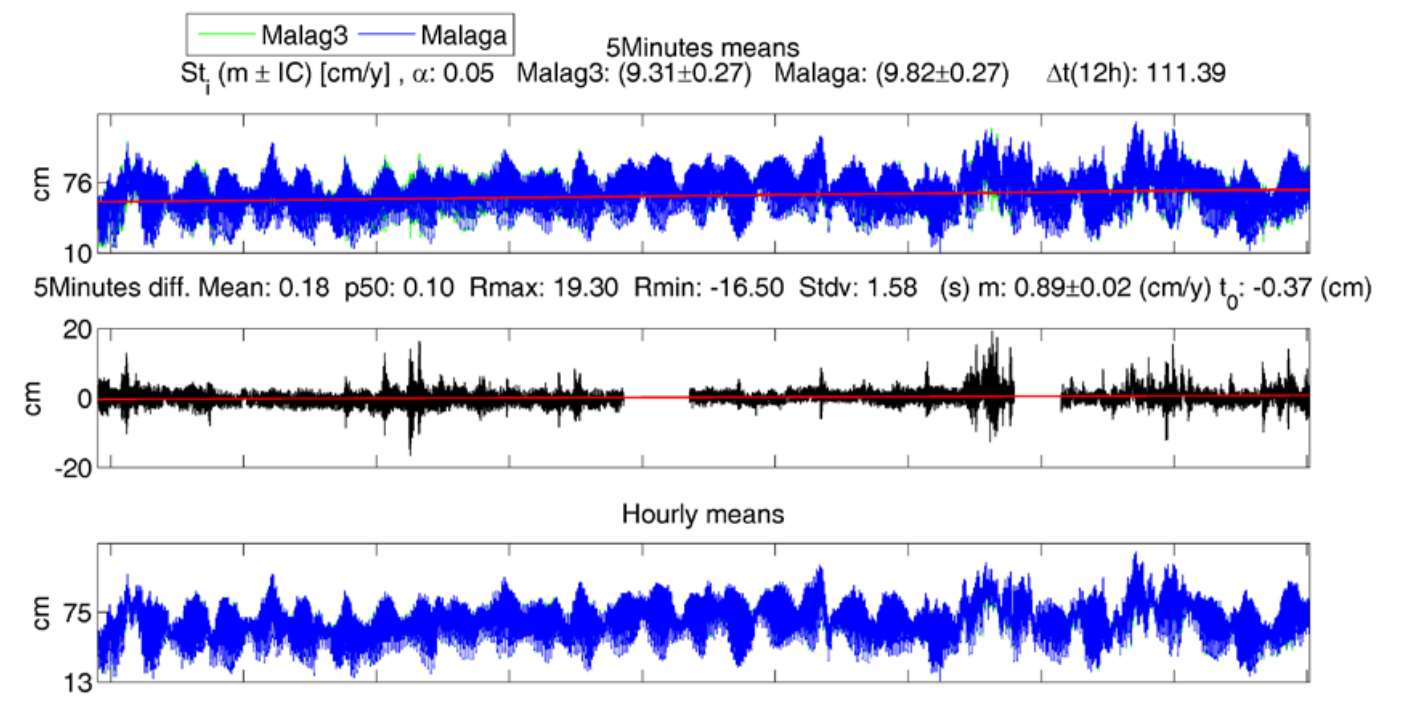

Hourly diff. Mean: 0.18 p50: 0.10 Rmax: $6.30 R \min :-4.80 \mathrm{Stdv}: 1.16$ (s) m: $0.89 \pm 0.06$ (cm/y) $t_{0}:-0.37$ (cm)
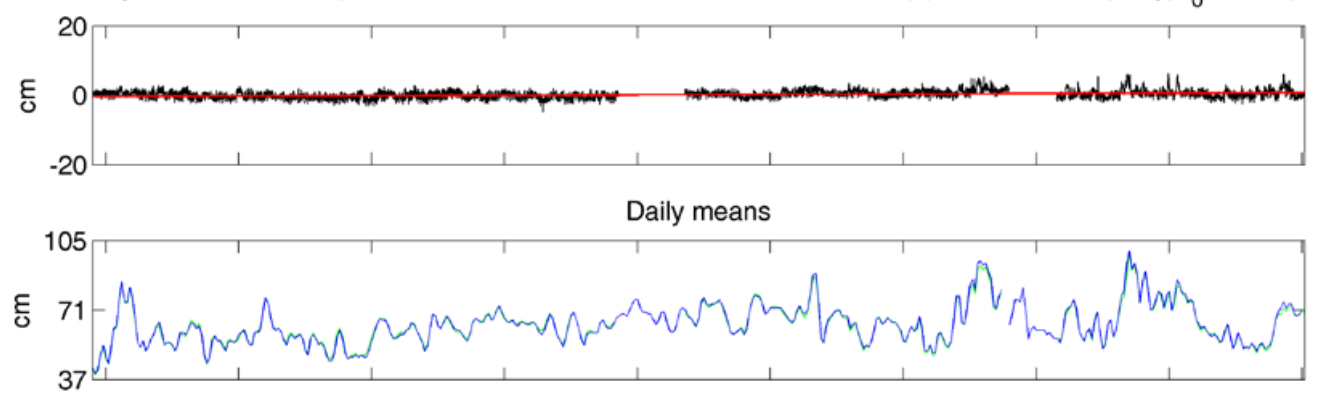

Daily diff. Mean: 0.19 p50: 0.10 Rmax: 4.70 Rmin: -2.00 Stdv: 0.88 (s) m: $0.92 \pm 0.21$ (cm/y) t: $:-0.37$ (cm)

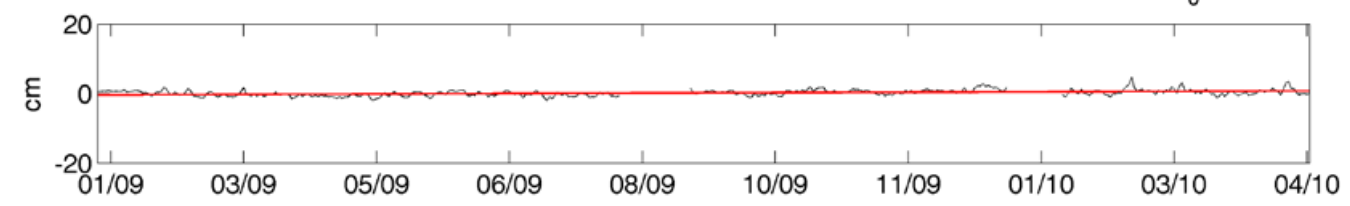

Fig. 5. Graphical representation of the comparison, including basic statistics, for Málaga (SRD) vs. Málaga3 (MIROS) stations. The slope of the linear trend $(\mathrm{m})$ is converted to $\mathrm{cm} \mathrm{yr}^{-1}$. The trend of both time series is similar (around $9 \mathrm{~cm} \mathrm{yr}^{-1}$ ), indicating no drift in either of the stations. Average time shift estimated from the main tidal period is $111.39 \mathrm{~s}$.

the redundancy period varies from 4 months to more than a year, the number of significant harmonic constants obtained will also be slightly different in each case. Results will be presented regarding the differences in the main tidal constituents and the residual or surge component for the two overlapping series at each station.

\subsubsection{Impact of the renovation on historical mean sea levels - use of altimetry data}

Another basic objective of a sea level network is the study of long-term mean sea level changes, for which daily, monthly and annual means are routinely computed from all tide gauges around the world. Monthly mean sea levels are compiled by the Permanent Service for Mean Sea Level (PSMSL) due to its interest in global climate change impact studies
(Woodworth and Player, 2003). From the small amplitude of long-term mean sea level changes in a historical record (several millimetres per year), it is particularly important to have a good datum connection and a careful study of the influence of instrumentation and/or location changes in a network.

Apart from the comparison of mean sea levels provided by old and new sensors, the main objective in this case was the generation of coherent and reliable historical mean sea level time series that combine data from the old and the new tide gauges. The presence of a significant bias between the old and the new sensors may influence future computation of trends more than a seasonal difference, for example, so we will focus in the identification of this bias, its magnitude and influence on the sea level trends, and its possible correction. The detailed study of several years of daily or monthly means will reveal less obvious errors that can affect sea level trends 


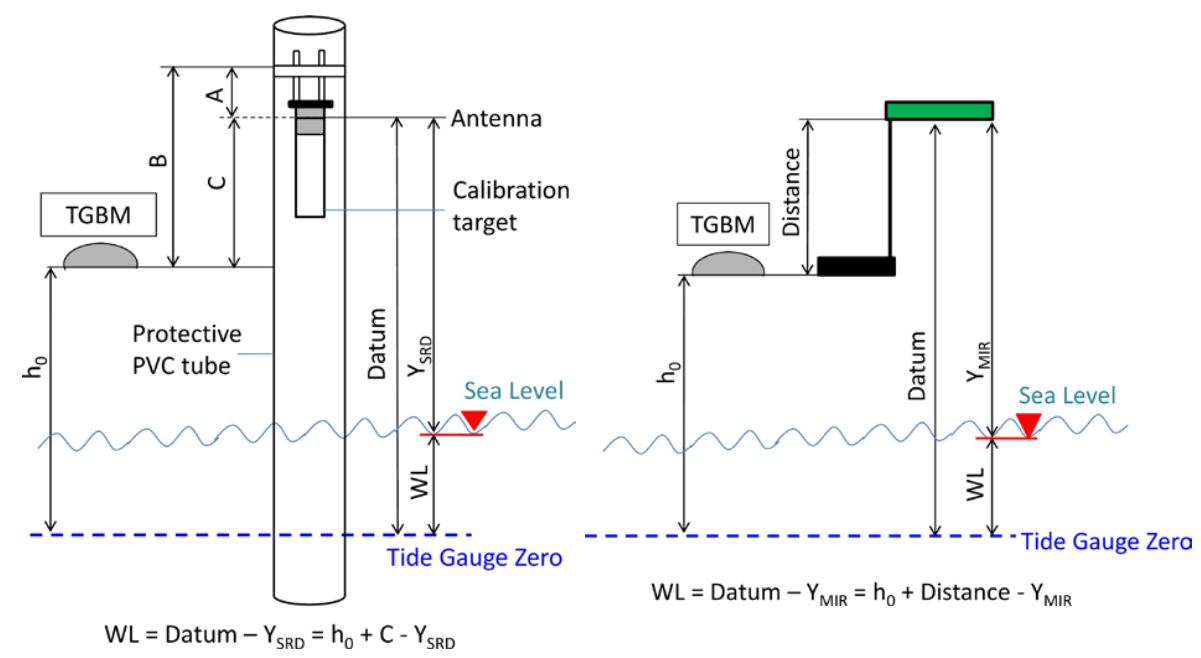

Fig. 6. Details of converting distance measurement from the acoustic SRD (left) and the radar MIROS (right) to water level relative to the datum (WL). The SRD measures inside a PVC tube to filter waves. Uncertainties in the datum (related to uncertainty in the levelling to the contact point and datum definition) and in the distance measurements from the different sensors ( $Y_{\mathrm{MIR}}$ and $\left.Y_{\mathrm{SRD}}\right)$ will influence the final accuracy of water level measurements (WL).

in the future, i.e. differences or biases of a few centimetres that may go unnoticed in operational applications.

Even stations that have been moved to another quay in the harbour should present practically the same behaviour in daily and monthly means as for the old one. Nevertheless, the situation is not always perfect and these are the many reasons for eventual differences in mean sea levels: imperfect datum connection, wrong operation or drift in one of the sensors, and differential vertical land movement of the station if located at a different quay. We can consider the scale error in one of the sensors as one of the second type of reasons because, as explained in Sect. 2.1, this usually results in a bias in the means.

One way of checking the reliability of this historical time series is comparing data with nearby stations (buddy checking), as seasonal and interannual variations should be similar. Taking into account the problem of delamination that caused additional bias in the mean sea levels during the last years in some MIROS antennas, altimetry data in the vicinity of each tide gauge have also been used as an external source of information.

Altimetry sea surface height time series in the vicinity of each tide gauge have been computed from AVISO Sea Level Anomaly (SLA) maps (http://www.aviso.oceanobs. com). These are gridded data obtained combining up to four different satellite altimetry missions at a given time (updated time series, based on Topex/Poseidon/Jason-1/Jason2/Envisat/GFO), which significantly increases the estimation of mesoscale signals (Le Traon and Dibarboure, 1999; Le Traon et al., 2001; Pascual et al., 2006), and that cover exactly the time period of the REDMAR network (since 1992 to present). We have used the global grid for the stations in the Atlantic coast, with a spatial resolution of $1 / 3 \times 1 / 3^{\circ}$ and a higher resolution grid available for the Mediterranean stations $\left(1 / 8 \times 1 / 8^{\circ}\right)$. In both cases the temporal resolution is seven days. These are final products provided by AVISO so they have all the environmental and instrumental corrections applied, including the inverse barometer and higher frequency meteorological effects (Dynamic Atmospheric Correction (DAC)). In order to compare with the tide gauge monthly means, we have eliminated this correction in altimetry data by adding again the DAC correction also provided by AVISO. As the DAC grid was not coincident with the SLA grids, an interpolation to the same grid was made. The altimetry time series in the vicinity of each tide gauge has been obtained, averaging both data sets to monthly means, adding the two components, and computing the spatial mean on a small grid of $0.5^{\circ}$ resolution near the harbour. There is a general good agreement in the variability of altimetry and tide gauge time series obtained in this way (correlation values range from 0.8 at Motril to larger than 0.9 at the northern coast and Canary Islands stations).

It is important to stress that altimetry mean sea levels in the vicinity of a tide gauge are not necessarily the same as the mean sea levels recorded by the tide gauge (Vinogradov and Ponte, 2011). Significant interannual variability differences may arise due to the existence of complex circulation patterns near the coast: influence of coastline geometry or bathymetry in open ocean and boundary waves propagation, different stratification, broadness of the continental shelf, tidal aliasing or proximity to major boundary currents. In addition, as the two technologies use different reference levels, altimetry providing absolute sea levels with respect to Earth's centre of mass, and tide gauges providing sea levels relative to the 
land, long-term trends may also differ significantly due to local, regional or global land movements in the tide gauge. All these signals may represent themselves differently at different locations and are difficult to determine, but this concern is not included in the scope of this work. Altimetry time series here are only intended to help in the identification of significant changes during the upgrade of technology or sensor and to check the continuity of the monthly means at the tide gauge station.

\section{Results and discussion}

\subsection{5 min data, hourly values and daily means}

Tables 3, 4, 5 and 6 summarize the main statistical results of the comparison study for the $5 \mathrm{~min}$, hourly, daily and monthly means respectively. Before making an interpretation of these data, it is very important to emphasize that, first, all of them are average estimates for the whole overlapping period and, second, that they have been computed maintaining the original sampling and time assignment strategy of the different sensors. This means that these values present an upper limit of the error and will be larger initially than what would be obtained from a more precise pre-processing of the time series.

Paying attention first to the bias column of Tables 3 to 6 , it becomes evident which stations are already reasonably referred to the same datum. This is the case for Huelva, Vigo, Santander, Málaga, Barcelona, Las Palmas and Hierro. The rest show bias ranging from $9.67 \mathrm{~cm}$ in Valencia to $1.23 \mathrm{~cm}$ in Tenerife (for the $5 \mathrm{~min}$ averages). For the stations where the sensors are at the same location (Ibiza, Coruña, Santander, Gijón and Bonanza) the bias should be related to scale error, malfunction or wrong datum assignment. The rest of stations may also show the influence of the different location in some way, although all of them have been connected by highprecision levelling and datum difference eliminated (Valencia and Motril, for example).

Woodworth and Smith (2003) stated that, provided the high-frequency noise in each of two compared sensors is of a similar magnitude, root mean square errors (in our case Stdv) values below $1.5 \mathrm{~cm}$ would yield a precision better than $1 \mathrm{~cm}$ for the individual sensors, which is consistent with Global Sea Level Observing System (GLOSS) standards (IOC, 2002). Table 3 shows that for the 5 min data, only Barcelona would fulfil this condition and if we look for the stations with Stdv below $2 \mathrm{~cm}$ in the same table, this happens at Hierro, Fuerteventura, Las Palmas, Vilagarcía, Málaga and Valencia. This is interesting as all these tide gauges are installed at different docks, so greater differences are expected to appear in the higher frequency phenomena. If we have a look to Table 4 (hourly values), then the GLOSS condition would be fulfilled for five of the seventeen pairs of stations: Las Palmas, Málaga, Motril, Barcelona and Valencia.
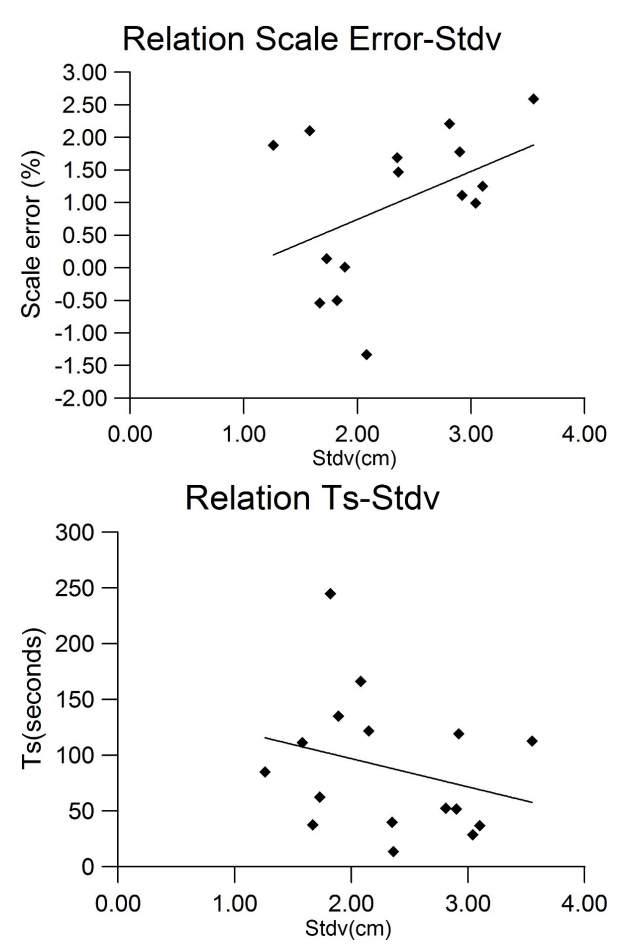

Fig. 7. Relation of scale error and time shift $\left(T_{\mathrm{S}}\right)$ with standard deviation of the differences (Stdv) for each pair of stations. Stdv normally increases for larger scale error (top) and decreases for smaller time shift (bottom). Anomalous values of scale error and $T_{\mathrm{S}}$ in Valencia and Ibiza not included here.

Of these five, four are based on SRD sensors, one (Motril) is based on a pressure sensor, and only Las Palmas, in the Canary Islands, has a relatively high tidal regime; in all these cases, as previously stated, the MIROS station is located in a different location inside the harbour. As expected, averaging the $5 \mathrm{~min}$ data to hourly, daily and monthly means progressively reduces in general the Stdv parameter.

This seems to indicate that there is not a clear correlation of the Stdv with the distance between the two sensors or the type of sensor, being apparently more related to the good performance during the period of study. In fact, the particular value of Stdv depends on both the scale error and the time shift (Fig. 7), not corrected here, e.g. we have to look at these Stdv values as upper limits to the error. In Las Palmas, Gijón, Bilbao and Barcelona, a MIROS delamination problem was present during or immediately after the overlapping period, but a correct determination of the influence on the data and their correction has been possible.

The linear correlation is very good for practically all the pairs of stations, $R$ being between 0.99 and 1.00 except at Ibiza. Also, this value is lower for $5 \mathrm{~min}$ data in the Mediterranean stations, Barcelona, Valencia, Motril and Ibiza, something expected due to the importance of high-frequency oscillations for this region. The estimated time shift $\left(T_{\mathrm{S}}\right)$ between $5 \mathrm{~min}$ time series for a $T=12.42 \mathrm{~h}$ are all within 
Table 3. Results obtained from the 5 min averaged time series. (Stdv: standard deviation of the differences, $R_{\max }:$ maximum difference, $R_{\text {min }}$ : minimum difference, $R$ : correlation coefficient, $\varepsilon$ : scale error (\%), $T_{\mathrm{S}}$ : average time shift from $\mathrm{M}_{2}$ period). $a, b$ : $y$ intercept and slope of the regression fit.

\begin{tabular}{|c|c|c|c|c|c|c|c|c|c|}
\hline St1/St2 & $\begin{array}{l}\text { Bias } \\
(\mathrm{cm})\end{array}$ & $\begin{array}{l}\text { Stdv } \\
(\mathrm{cm})\end{array}$ & $\begin{array}{r}R_{\max } \\
(\mathrm{cm})\end{array}$ & $\begin{array}{c}R_{\min } \\
(\mathrm{cm})\end{array}$ & $a$ & $b$ & $R$ & $\begin{array}{r}\varepsilon \\
(\%)\end{array}$ & $\begin{array}{l}T_{\mathrm{S}} \\
(\mathrm{s})\end{array}$ \\
\hline Bil3/Bilb & 4.72 & 3.04 & 29.90 & -19.70 & 2.33 & 1.0099 & 1.00 & 0.99 & 28.76 \\
\hline San2/Sant & -0.75 & 2.90 & 11.50 & -24.90 & -5.85 & 1.0178 & 1.00 & 1.78 & 51.85 \\
\hline Gij2/Gijo & -2.57 & 2.36 & 36.80 & -34.70 & -6.60 & 1.0147 & 1.00 & 1.47 & 13.65 \\
\hline Cor2/Coru & -2.14 & 2.35 & 12.60 & -16.60 & -6.73 & 1.0169 & 1.00 & 1.69 & 39.94 \\
\hline Vil2/Vill & 1.52 & 1.71 & 8.20 & -11.50 & 1.27 & 1.0011 & 1.00 & 0.11 & -49.00 \\
\hline Vig2/Vigo & -0.71 & 2.92 & 32.90 & -22.80 & -3.03 & 1.0111 & 1.00 & 1.11 & -119.32 \\
\hline Hue5/Huel & 0.23 & 3.10 & 26.30 & -29.70 & -2.30 & 1.0125 & 1.00 & 1.25 & 36.91 \\
\hline Bon2/Bona & 5.01 & 3.30 & 20.60 & -17.00 & 0.32 & 1.0261 & 1.00 & 2.61 & 112.50 \\
\hline Mal3/Mala & 0.18 & 1.58 & 19.30 & -16.50 & -1.16 & 1.0210 & 1.00 & 2.10 & 111.39 \\
\hline Mot2/Motr & -3.06 & 2.08 & 24.50 & -46.40 & -2.55 & 0.9867 & 0.99 & -1.33 & 165.78 \\
\hline Val3/Vale & 9.67 & 1.97 & 23.05 & -4.35 & 14.58 & 0.9579 & 0.98 & -4.21 & 267.13 \\
\hline Bar2/Barc & -0.81 & 1.26 & 15.50 & -10.30 & -1.40 & 1.0188 & 0.99 & 1.88 & 84.90 \\
\hline Ibi2/Ibiz & 1.25 & 2.15 & 13.00 & -7.60 & 4.42 & 0.9210 & 0.98 & -7.90 & 121.67 \\
\hline Ten2/Tene & 1.23 & 2.57 & 42.40 & -38.50 & -2.29 & 1.0226 & 1.00 & 2.26 & 51.90 \\
\hline Las2/LasP & -0.01 & 1.67 & 8.70 & -22.00 & 0.86 & 0.9946 & 1.00 & -0.54 & 37.45 \\
\hline Fue2/Fuer & 4.26 & 1.89 & 24.50 & -14.20 & 4.24 & 1.0001 & 1.00 & 0.01 & 135.01 \\
\hline Hie2/Hier & -0.30 & 1.82 & 7.50 & -12.40 & 0.50 & 0.9950 & 1.00 & -0.50 & 244.81 \\
\hline
\end{tabular}

Table 4. Results obtained from the hourly averaged time series. (Stdv: standard deviation of the differences, $R_{\max }$ : maximum difference, $R_{\text {min }}$ : minimum difference, $R$ : correlation coefficient, $\varepsilon$ : scale error $(\%)$ ). $a, b: y$ intercept and slope of the regression fit.

\begin{tabular}{|c|c|c|c|c|c|c|c|c|}
\hline $\mathrm{St} 1 / \mathrm{St} 2$ & $\begin{array}{l}\text { Bias } \\
(\mathrm{cm})\end{array}$ & $\begin{array}{l}\text { Stdv } \\
(\mathrm{cm})\end{array}$ & $\begin{array}{r}R_{\max } \\
(\mathrm{cm})\end{array}$ & $\begin{array}{r}R_{\min } \\
(\mathrm{cm})\end{array}$ & $a$ & $b$ & $R$ & $\begin{array}{r}\varepsilon \\
(\%)\end{array}$ \\
\hline Bil3/Bilb & 4.70 & .28 & 12.10 & -5.30 & 2.30 & 1.0099 & 1.00 & 0.99 \\
\hline San2/Sant & -0.76 & 2.76 & 5.80 & -10.40 & -5.86 & 1.0178 & 1.00 & 1.78 \\
\hline Gij2/Gijo & -2.55 & 1.78 & 5.50 & -10.90 & -6.52 & 1.0145 & 1.00 & 1.45 \\
\hline Cor2/Coru & -2.15 & 2.04 & 4.30 & -12.00 & -6.76 & 1.0170 & 1.00 & 1.70 \\
\hline Vil2/Vill & 1.52 & 1.60 & 7.30 & -5.00 & 1.26 & 1.0012 & 1.00 & 0.12 \\
\hline Vig2/Vigo & -0.71 & 2.54 & 8.90 & -11.10 & -3.02 & 1.0111 & 1.00 & 1.11 \\
\hline Hue5/Huel & 0.23 & 2.82 & 8.50 & -9.80 & -2.32 & 1.0126 & 1.00 & 1.26 \\
\hline Bon2/Bona & 5.01 & 3.04 & 16.90 & -10.40 & 0.30 & 1.0262 & 1.00 & 2.62 \\
\hline Mal3/Mala & 0.18 & 1.16 & 6.30 & -4.80 & -1.50 & 1.0264 & 1.00 & 2.64 \\
\hline Mot2/Motr & -3.06 & 1.04 & 1.90 & -6.90 & -2.90 & 0.9959 & 1.00 & -0.41 \\
\hline Val3/Vale & 9.72 & 1.12 & 14.35 & 2.45 & 13.71 & 0.9658 & 0.99 & -3.42 \\
\hline Bar2/Barc & -0.81 & 0.95 & 2.50 & -4.00 & -1.47 & 1.0212 & 1.00 & 2.12 \\
\hline Ibi2/Ibiz & 1.24 & 2.01 & 6.70 & -5.10 & 4.36 & 0.9221 & 0.98 & -7.79 \\
\hline Ten2/Tene & 1.19 & 2.14 & 17.10 & -13.40 & -2.37 & 1.0229 & 1.00 & 2.29 \\
\hline Las2/LasP & -0.02 & 1.44 & 6.20 & -9.50 & 0.81 & 0.9950 & 1.00 & -0.52 \\
\hline Fue2/Fuer & 4.25 & 1.70 & 15.80 & -6.30 & 4.25 & 1.0000 & 1.00 & 0.00 \\
\hline Hie2/Hier & -0.29 & 1.78 & 4.70 & -5.90 & 0.49 & 0.9951 & 1.00 & -0.49 \\
\hline
\end{tabular}

\pm 3.3 min except at Valencia and Hierro; the large value of $T_{\mathrm{s}}$ at Valencia is not realistic due to the small amplitude of the semidiurnal tide ( $T=12.42 \mathrm{~h}$ ), the period used for its computation. As mentioned before, clock malfunctions related to these time shifts are expected to come from the old sensors, as there is practically no shift for the MIROS GPS control of time. This has of course been checked and confirmed in the routine visits to the stations.

\subsection{The scale error origin and effects}

We have detected important scale errors in practically all the stations (Tables 3, 4 and 7), in comparison to the ones found in other works (Woodworth and Smith, 2003; Martín Míguez et al., 2005). These values can be affected by the lack of correction of the observed time shifts (something normally adjusted in previous experiments) and by the different locations 
Table 5. Results obtained from the daily averaged time series. (Stdv: standard deviation of the differences, $R_{\max }:$ maximum difference, $R_{\min }$ : minimum difference, $R$ : correlation coefficient). $a, b: y$ intercept and slope of the regression fit.

\begin{tabular}{lrrrrrrr}
\hline St1/St2 & $\begin{array}{r}\text { Bias } \\
(\mathrm{cm})\end{array}$ & $\begin{array}{r}\text { Stdv } \\
(\mathrm{cm})\end{array}$ & $\begin{array}{r}R_{\max } \\
(\mathrm{cm})\end{array}$ & $\begin{array}{r}R_{\min } \\
(\mathrm{cm})\end{array}$ & $a$ & $b$ & $R$ \\
\hline Bil3/Bilb & 4.69 & 1.49 & 8.00 & 0.20 & 12.40 & 0.9681 & 0.99 \\
San2/Sant & -0.76 & 1.72 & 2.80 & -5.80 & -9.04 & 1.0289 & 0.99 \\
Gij2/Gijo & -2.58 & 0.52 & -1.20 & -4.50 & -4.01 & 1.0052 & 1.00 \\
Cor2/Coru & -2.17 & 0.66 & -0.80 & -3.90 & 0.58 & 0.9898 & 0.99 \\
Vil2/Vill & 1.50 & 0.93 & 4.10 & -0.90 & 3.31 & 0.9916 & 0.99 \\
Vig2/Vigo & -0.69 & 0.83 & 2.10 & -3.60 & -0.16 & 0.9975 & 1.00 \\
Hue5/Huel & 0.24 & 1.99 & 4.50 & -4.50 & -4.37 & 1.0228 & 0.96 \\
Bon2/Bona & 4.99 & 1.11 & 8.00 & 2.10 & 8.77 & 0.9790 & 1.00 \\
Mal3/Mala & 0.19 & 0.88 & 4.70 & -2.00 & -2.45 & 1.0414 & 1.00 \\
Mot2/Motr & -3.06 & 0.64 & -0.30 & -4.30 & -3.41 & 1.0093 & 1.00 \\
Val3/Vale & 9.73 & 0.73 & 11.15 & 7.75 & 14.22 & 0.9615 & 1.00 \\
Bar2/Barc & -0.79 & 0.68 & 1.10 & -2.30 & -1.43 & 1.0202 & 1.00 \\
Ibi2/Ibiz & 1.25 & 1.85 & 5.10 & -2.20 & 4.75 & 0.9121 & 0.98 \\
Ten2/Tene & 1.20 & 0.79 & 3.40 & -1.60 & -0.19 & 1.0090 & 0.99 \\
Las2/LasP & -0.03 & 0.52 & 1.40 & -1.70 & 4.19 & 0.9738 & 1.00 \\
Fue2/Fuer & 4.27 & 0.71 & 6.90 & 2.00 & 9.17 & 0.9682 & 0.99 \\
Hie2/Hier & -0.29 & 0.41 & 1.40 & -1.40 & -0.21 & 0.9995 & 1.00 \\
\hline
\end{tabular}

Table 6. Results obtained from the monthly averaged time series. (Stdv: standard deviation of the differences, $R_{\max }:$ maximum difference, $R_{\text {min }}:$ minimum difference, $R$ : correlation coefficient). $a, b: y$ intercept and slope of the regression fit.

\begin{tabular}{lrrrrrrr}
\hline St1/St2 & $\begin{array}{r}\text { Bias } \\
(\mathrm{cm})\end{array}$ & $\begin{array}{r}\text { Stdv } \\
(\mathrm{cm})\end{array}$ & $\begin{array}{r}R_{\max } \\
(\mathrm{cm})\end{array}$ & $\begin{array}{r}R_{\min } \\
(\mathrm{cm})\end{array}$ & $a$ & $b$ & $R$ \\
\hline Bil3/Bilb & 4.87 & 0.90 & 5.70 & 3.20 & 15.02 & 0.9580 & 0.99 \\
San2/Sant & -0.47 & 1.48 & 1.60 & -2.70 & 27.20 & 0.9035 & 0.90 \\
Gij2/Gijo & -2.77 & 0.15 & -2.60 & -2.90 & -12.21 & 1.0345 & 1.00 \\
Cor2/Coru & -2.45 & 1.03 & -1.80 & -4.40 & 22.60 & 0.9075 & 0.96 \\
Vil2/Vill & 1.42 & 0.76 & 2.60 & 0.20 & 1.81 & 0.9982 & 0.98 \\
Vig2/Vigo & -0.60 & 0.70 & 1.30 & -1.50 & 2.59 & 0.9847 & 1.00 \\
Hue5/Huel & 0.23 & 1.99 & 2.90 & -3.70 & -14.87 & 1.0746 & 0.92 \\
Bon2/Bona & 4.90 & 0.83 & 6.30 & 3.70 & 14.95 & 0.9443 & 1.00 \\
Mal3/Mala & 0.25 & 0.46 & 1.30 & -0.40 & -2.91 & 1.0492 & 1.00 \\
Mot2/Motr & -3.19 & 0.25 & -2.80 & -3.60 & -3.99 & 1.0209 & 1.00 \\
Val3/Vale & 9.95 & 0.70 & 10.45 & 9.15 & 31.51 & 0.8153 & 1.00 \\
Bar2/Barc & -0.84 & 0.58 & 0.00 & -1.60 & -1.98 & 1.0360 & 1.00 \\
Ibi2/Ibiz & 2.08 & 1.30 & 4.00 & 0.10 & 8.45 & 0.8327 & 0.99 \\
Ten2/Tene & 1.13 & 0.81 & 2.70 & 0.30 & -19.28 & 1.1312 & 0.98 \\
Las2/LasP & -0.02 & 0.39 & 0.50 & -0.90 & 7.31 & 0.9552 & 1.00 \\
Fue2/Fuer & 4.14 & 0.60 & 4.70 & 2.90 & 25.25 & 0.8639 & 0.99 \\
Hie2/Hier & -0.13 & 0.40 & 0.40 & -0.70 & 1.78 & 0.9881 & 0.99 \\
\hline
\end{tabular}

inside the harbours, and will more probably be related to instrumental problems for those stations located at exactly the same position: Santander, Gijón, Coruña, Huelva, Bonanza, Ibiza and Tenerife. For example, the estimated scale error derived from the $5 \mathrm{~min}$ and hourly time series does not differ significantly for all the Atlantic stations but it is systematically different for the Mediterranean stations, Motril, Málaga, Valencia and Barcelona, where higher frequency variability may differ more due to the "seiches" effect and different resonance responce at different harbour docks.

Although not all the scale errors obtained in this way have the same origin, all the high values have been found to be due to the old acoustic or pressure sensors; their values are positive for the SRD based stations at the same location, indicating larger tidal ranges in these old sensors, and negative or very small for the AAND based stations (lower tidal ranges in the AAND sensors). Valencia and Ibiza present 
Table 7. Bias (from hourly values) and scale error $\varepsilon$ (from $5 \mathrm{~min}$ and hourly values) for all the stations. Fourth column contains the distance in metres between the old and the new station and the fifth column the evidence of the scale error in the Van de Casteele plot. The scale error is clear in 7 stations (bold), all of them based on SRD sensors. Additional unexplained bias remains in some stations (*).

\begin{tabular}{lrrrr}
\hline Station & $\begin{array}{r}\text { Bias } \\
(\mathrm{cm})\end{array}$ & $\begin{array}{r}\text { Scale error } \varepsilon \\
\text { min/hourly }(\%)\end{array}$ & $\begin{array}{r}\text { Distance } \\
\text { SRD/AAND-MIROS }(\mathrm{m})\end{array}$ & $\begin{array}{r}\text { Influence Van } \\
\text { de Casteele }\end{array}$ \\
\hline Bilb* & $\mathbf{4 . 7 0}$ & $\mathbf{0 . 9 9 / 0 . 9 9}$ & $\mathbf{1 0 0 0}$ & Yes \\
Sant & $\mathbf{- 0 . 7 6}$ & $\mathbf{1 . 7 8 / 1 . 7 8}$ & $\mathbf{0}$ & Yes \\
Gijo & $\mathbf{- 2 . 5 5}$ & $\mathbf{1 . 4 7 / 1 . 4 5}$ & $\mathbf{5}$ & Yes \\
Coru & $\mathbf{- 2 . 1 5}$ & $\mathbf{1 . 6 9 / 1 . 7 0}$ & $\mathbf{0}$ & Yes \\
Vill & 1.52 & $0.11 / 0.12$ & 313 & No \\
Vigo & -0.71 & $1.11 / 1.11$ & 250 & No \\
Huel & $\mathbf{0 . 2 3}$ & $\mathbf{1 . 2 5 / 1 . 2 6}$ & $\mathbf{0}$ & Yes \\
Bona & $\mathbf{5 . 0 1}$ & $\mathbf{2 . 5 9 / 2 . 6 2}$ & $\mathbf{0}$ & Yes \\
Mala & 0.18 & $2.10 / 2.64$ & 180 & No \\
Motr* & -3.06 & $-1.33 /-0.41$ & 600 & No \\
Vale* & 9.72 & $-4.21 /-3.42$ & 2500 & No \\
Barc & -0.81 & $1.88 / 2.12$ & 915 & No \\
Ibiz & 1.24 & $-7.90 /-7.79$ & 0 & No \\
Tene & $\mathbf{1 . 1 9}$ & $\mathbf{2 . 2 6 / 2 . 2 9}$ & $\mathbf{0}$ & Yes \\
LasP & -0.02 & $-0.54 /-0.52$ & 523 & No \\
Fuer* & 4.25 & $0.01 / 0.00$ & 422 & No \\
Hier & -0.29 & $-0.50 /-0.49$ & 125 & No \\
\hline
\end{tabular}

particularly large negative values. In the case of Valencia, as mentioned above, this is probably due to real differences in the higher frequency signals, very important here where the distance between tide gauges is $2.5 \mathrm{~km}$ and the new sensor is much more exposed to wind waves. The large scale error in Ibiza ( $-7.9 \%$ for $5 \mathrm{~min}$ averages), however, should be interpreted as a consequence of the difference in the seasonal cycle, due to a feature of the pressure sensor that does not take into account the changes of density through the year. For these reasons, both Valencia and Ibiza values of scale error were not included in Fig. 7.

Table 7 summarizes the bias, the scale error and its influence in the Van de Casteele plots for the overlapping period. The table shows that the effect is clear in 7 of the stations, all of them based on SRD sensors, confirming that these sensors measured slightly lower low waters. When they are corrected, the bias between the time series falls well within the uncertainty limits defined for datum definition in each type of tide gauge and coincides with the existing datum difference after levelling at 10 of the stations. Unexplained biases remain in the rest.

Looking into the detail in Table 7 and the Van de Casteele plots (Fig. 8) before and after correction of the scale error (slope of the regression fit), one can classify the influence of the scale error in the data according to the following situations:

- Case A: stations with scale error $>0.9 \%$ :

- Case A1: the Van de Cateele plots show a clear inclination for the $5 \mathrm{~min}$ and hourly levels (not for the daily means), revealing a difference in the tidal range. Correction of the scale error eliminates this inclination and generates a bias between the original and corrected time series for Bilbao, Santander, Gijón, Coruña, Huelva, Bonanza and Tenerife (Fig. 8, upper plot: Gijón station).

- Case A2: the Van de Casteele plots do not show inclination of the time series and the scale error correction only generates a bias between original and corrected time series ( $5 \mathrm{~min}$, hourly and daily means) for Vigo, Málaga, Valencia, Barcelona and Ibiza. Figure 8 (middle plot) shows an example of this situation for Vigo. Ibiza is a special case; an inclination in the daily means, coherent with a seasonal variation observed in the daily means differences, disappears when correcting its large scale error, revealing only a significant bias change in all the time series (Fig. 8, bottom plot).

- Case B: stations with scale error $<0.9 \%$ : Vilagarcía, Las Palmas, Fuerteventura, Hierro and Motril (for hourly values).

In general, for all the stations the bias obtained in the time series comparison is explained by the above mentioned scale error, except at Bilbao, where approximately $50 \%$ of the bias $(4.7 \mathrm{~cm})$ is explained by the scale error, but the other $50 \%$ could be due to the distance between tide gauges $(1 \mathrm{~km})$ or to an incorrect datum definition in the old sensor. Similar reasons could apply to Motril (wrong performance of the 

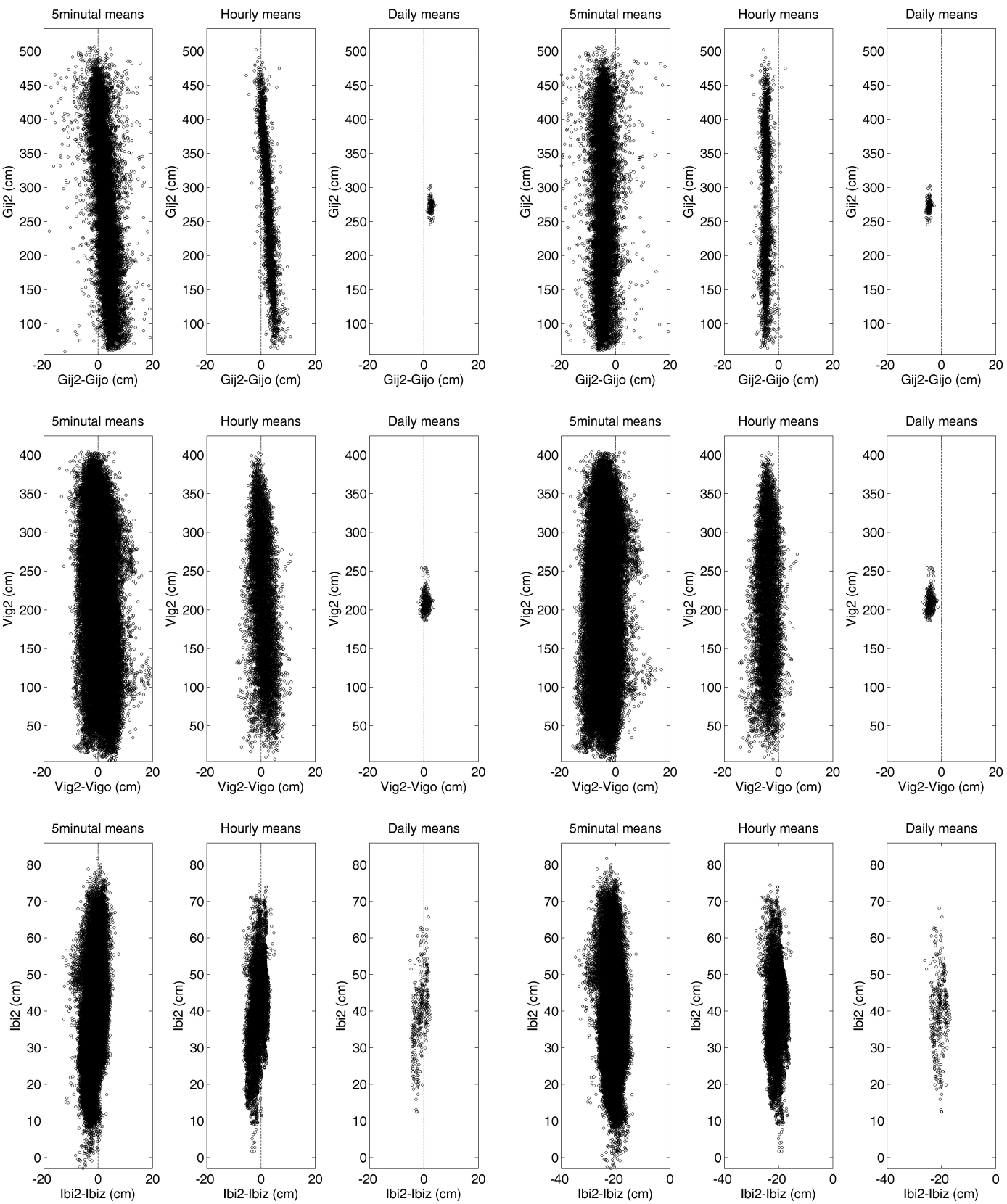

Fig. 8. Van de Casteele plots for $5 \mathrm{~min}$, hourly and daily values for the original data (left panels) and for the same data after scale error correction applied (right panel) for Gijón (top panel, case A1), Vigo (middle panel, case A2) and Ibiza (bottom panel, A2, special case). The value of the scale error in Ibiza is large ( $-7.79 \%$ for hourly values) and results in a clear inclination in daily means, coherent with the differences observed in the seasonal cycle. Correction of this large scale error implies a significant bias change in all the time series.

AAND sensor at the end of its operation), Valencia (distance of $2.5 \mathrm{~km}$ between stations as well as datum problems in the historical SRD station) and Fuerteventura.

Of the 5 stations of case B (scale error below $0.9 \%$ ), only two are SRD-based stations (Vilagarcía and Las Palmas) and three AAND-based stations. Bilbao and Vigo present relatively small values of the scale error in comparison to the rest of the SRD stations. Interestingly, none of these new stations are located at exactly the same place as the corresponding old ones, which indicates that the wave and other environment conditions are not significantly different. Most of the stations with significant tidal range, except Vilagarcía, show however important scale error in spite of being located at exactly the same position. 
In summary, a clear scale error appears in several SRD sensors, normally at stations with important tidal range (Tables 3 to 7). Its influence affects basically the $5 \mathrm{~min}$ and hourly values and is reflected as a bias in the daily and monthly means. It seems reasonable to recommend trying its correction for the whole historical time series (in some cases $20 \mathrm{yr}$ of data) if one wants to be certain about its reliability for providing accurate tidal products and extreme sea level analysis. A small seasonal signal related to seasonal variations of temperature is apparent in the monthly and daily means at the SRD stations but its effect is negligible in the final trends, so we focus here in the mentioned bias that should be taken into account if it is larger than $1 \mathrm{~cm}$ (Sect. 4.4). Practically all the stations in the Mediterranean, where the tides are smaller, show little influence of the scale error in the hourly values but do present in some cases large differences in the $5 \mathrm{~min}$ data that the scale error correction eliminates. In all the cases except Ibiza station, this may be related to important physical differences in the signal because of the different location of the sensors, and it is not necessarily related to instrumental errors.

\subsection{Results of tide and surge comparison}

The scale error affects the tide computation with generally larger amplitudes for the semidiurnal constituents obtained from the SRD sensors. Table 8 contains the amplitude and phase of the main semidiurnal, diurnal and long-period harmonic constants for each pair of stations, obtained for the overlapping period. As already mentioned, the set of harmonics obtained differs slightly depending on the length of this period. For this reason $S_{\mathrm{a}}$ and $S_{\mathrm{sa}}$ harmonic constants (annual and semiannual) are not available for some of the stations.

The main result from Table 8 is that practically all the stations originally based on SRD sensors (except Las Palmas, Vilagarcía and Mediterranean stations with non-semidiurnal regime) show slightly lower $(\sim 1-2 \%)$ amplitude in the semidiurnal components (mainly $M_{2}$ and $S_{2}$ ) derived from the new MIROS sensor. This is consistent with the scale error present at all these stations and, as explained, is due to the SRD sensors. This is something that does not happen when comparing with the pressure sensors (Hierro, Ibiza, Motril and Fuerteventura). In Ibiza station, however, there is a significant difference in the annual and semiannual $\left(S_{\mathrm{a}}\right.$ and $S_{\mathrm{sa}}$ ) constituents, consistent with the problem detected in the pressure sensor, as explained in previous sections. The differences in these constituents, when available, are related to observed seasonal variations in the differences at some acoustic and pressure sensors (notice however, the similar values of these constituents in all the pressure sensors except Ibiza).

Table 9 shows the statistical parameters of the comparison of the residual time series for the same period (obtained from the previously obtained harmonic constants) and Fig. 9 shows the graphical comparison for Bilbao and Valencia. In the residual comparisons, a few spikes of $\pm 10 \mathrm{~cm}$ were
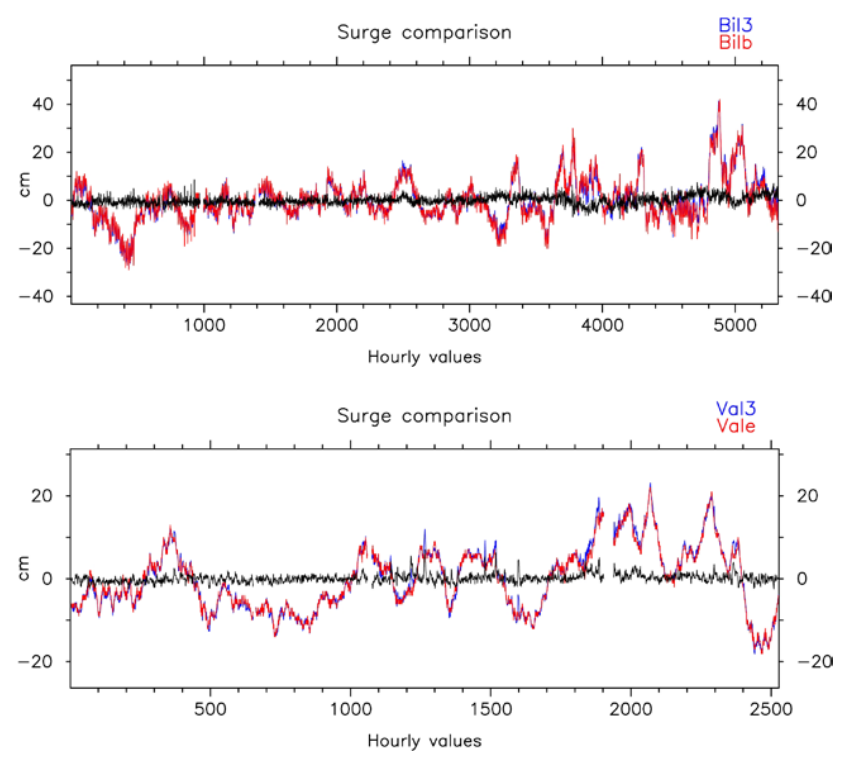

Fig. 9. Comparison of the hourly residual time series (blue for the new station, red for the old one, black for the differences), for around 4 months of redundancy period at Bilbao (top) and Valencia (bottom).

identified and eliminated, although the results did not change significantly if they were included. These spikes were usually related to the old station. Table 9 and Fig. 9 show a good performance for both tide gauges for storm surge applications at practically all the stations. The Stdv of the differences is under $1.5 \mathrm{~cm}$ for 12 of the 17 stations. Bonanza, Bilbao and Gijón present Stdv values greater than $1.8 \mathrm{~cm}(1.82$, 1.83 and $1.89 \mathrm{~cm}$ respectively). The correlation index is normally 0.98 or 0.99 except at Tenerife where it is 0.95 . As the main problems seem to be related to deficiencies in the old stations (e.g. Tenerife, Coruña, Bonanza or Ibiza), this confirms the capability of the new MIROS sensors to measure storm surges with sufficient accuracy. Nevertheless, in some cases there is an effect of high waves in the surge component, which is revealed by a sudden increase in the hourly residual of around $5 \mathrm{~cm}$ in the MIROS sensor. This is the case in Valencia, where sudden small surges were not recorded by the $\mathrm{SRD}$, in a more sheltered and interior dock, but were measured by the MIROS, closer to the mouth of the harbour and exposed to waves of more than $1 \mathrm{~m}$ during this time (Fig. 10). This could slightly affect extreme analysis studies, but not mean sea level, as we see in the next section.

\subsection{Mean sea levels}

Statistical results of the comparison of daily and monthly mean sea levels for the redundancy period are included in Tables 5 and 6 respectively. In this case, the Stdv becomes normally very small and the correlation index is practically 1 for all the stations. The number of data available for daily means 
Table 8. Main harmonic constants obtained from the two sensors for the overlapping period at each station. ( $S_{\mathrm{a}}$ and $S_{\mathrm{sa}}$ not available at the stations where this overlapping period was too short).

\begin{tabular}{|c|c|c|c|c|c|c|c|c|c|c|c|c|}
\hline \multirow[t]{2}{*}{ Station } & \multicolumn{2}{|c|}{$M_{2}$} & \multicolumn{2}{|c|}{$S_{2}$} & \multicolumn{2}{|c|}{$O_{1}$} & \multicolumn{2}{|c|}{$K_{1}$} & \multicolumn{2}{|c|}{$S_{\mathrm{A}}$} & \multicolumn{2}{|c|}{$S_{\mathrm{SA}}$} \\
\hline & $\begin{array}{l}\text { Amp } \\
(\mathrm{cm})\end{array}$ & $\begin{array}{r}\text { Phase } \\
\left({ }^{\circ}\right)\end{array}$ & $\begin{array}{l}\text { Amp } \\
(\mathrm{cm})\end{array}$ & $\begin{array}{r}\text { Phase } \\
\left({ }^{\circ}\right)\end{array}$ & $\begin{array}{l}\text { Amp } \\
(\mathrm{cm})\end{array}$ & $\begin{array}{r}\text { Phase } \\
\left({ }^{\circ}\right)\end{array}$ & $\begin{array}{l}\text { Amp } \\
(\mathrm{cm})\end{array}$ & $\begin{array}{r}\text { Phase } \\
\left({ }^{\circ}\right)\end{array}$ & $\begin{array}{l}\text { Amp } \\
(\mathrm{cm})\end{array}$ & $\begin{array}{r}\text { Phase } \\
\left({ }^{\circ}\right)\end{array}$ & $\begin{array}{l}\text { Amp } \\
(\mathrm{cm})\end{array}$ & $\begin{array}{r}\text { Phase } \\
\left({ }^{\circ}\right)\end{array}$ \\
\hline Bilb & 131.96 & 92.88 & 46.15 & 122.86 & 7.13 & 320.31 & 6.47 & 70.35 & & & 7.34 & 134.44 \\
\hline Bil3 & 130.64 & 92.65 & 45.55 & 122.71 & 7.10 & 321.45 & 6.46 & 70.75 & & & 7.96 & 136.99 \\
\hline Sant & 134.07 & 93.57 & 46.78 & 126.38 & 7.06 & 321.81 & 6.41 & 70.34 & 2.62 & 272.30 & 2.23 & 119.07 \\
\hline San2 & 131.76 & 93.28 & 45.94 & 125.95 & 6.92 & 321.53 & 6.17 & 70.30 & 1.81 & 320.40 & 2.29 & 113.50 \\
\hline Gijo & 130.61 & 91.25 & 45.69 & 123.45 & 6.89 & 322.25 & 6.74 & 70.29 & 2.76 & 280.62 & 2.43 & 144.47 \\
\hline Gij2 & 128.74 & 91.38 & 44.93 & 123.45 & 6.80 & 322.80 & 6.53 & 70.36 & 3.17 & 297.08 & 2.79 & 141.65 \\
\hline Coru & 120.01 & 86.63 & 40.77 & 116.43 & 6.55 & 323.84 & 7.86 & 72.50 & & & 1.69 & 42.48 \\
\hline Cor2 & 118.04 & 86.47 & 40.06 & 116.35 & 6.49 & 323.69 & 7.29 & 70.20 & & & 2.31 & 46.66 \\
\hline Vill & 113.86 & 78.54 & 39.95 & 108.23 & 6.40 & 319.58 & 7.33 & 62.98 & 1.74 & 41.50 & 1.02 & 264.53 \\
\hline Vil2 & 113.82 & 79.17 & 39.63 & 108.84 & 6.38 & 319.89 & 7.29 & 62.75 & 2.00 & 23.84 & 0.89 & 235.06 \\
\hline Vigo & 111.44 & 76.44 & 38.58 & 106.05 & 6.56 & 318.63 & 7.34 & 59.70 & 4.37 & 318.15 & 3.22 & 161.51 \\
\hline Vig2 & 110.12 & 77.44 & 38.41 & 106.86 & 6.45 & 319.00 & 7.07 & 62.43 & 4.60 & 320.79 & 2.81 & 159.44 \\
\hline Huel & 105.34 & 57.06 & 38.50 & 83.83 & 5.76 & 310.34 & 6.37 & 46.62 & 4.74 & 224.38 & 1.99 & 49.69 \\
\hline Hue5 & 104.23 & 56.95 & 37.36 & 83.33 & 5.82 & 309.93 & 6.27 & 45.31 & 3.32 & 254.94 & 2.31 & 64.55 \\
\hline Bona & 92.58 & 64.56 & 31.58 & 91.39 & 6.25 & 323.31 & 6.40 & 65.04 & & & 7.83 & 320.46 \\
\hline Bon2 & 90.11 & 63.64 & 30.41 & 90.73 & 6.21 & 322.62 & 6.23 & 62.49 & & & 8.22 & 320.79 \\
\hline Mala & 19.17 & 49.95 & 7.37 & 74.67 & 1.76 & 120.76 & 3.19 & 151.72 & 4.13 & 293.48 & 2.33 & 274.92 \\
\hline Mal3 & 18.77 & 49.13 & 7.23 & 74.43 & 1.73 & 119.96 & 3.23 & 152.38 & 3.69 & 284.81 & 2.47 & 278.68 \\
\hline Motr & 15.33 & 48.90 & 6.10 & 73.58 & 1.93 & 121.78 & 3.11 & 154.24 & & & 4.28 & 102.69 \\
\hline Mot2 & 15.49 & 47.64 & 6.06 & 73.56 & 1.91 & 121.82 & 3.25 & 152.47 & & & 4.29 & 105.17 \\
\hline Vale & 1.77 & 196.19 & 0.55 & 158.08 & 2.26 & 107.60 & 3.72 & 162.72 & & & & \\
\hline Val3 & 1.86 & 198.04 & 0.68 & 193.60 & 2.37 & 109.08 & 3.59 & 168.30 & & & & \\
\hline Barc & 4.63 & 213.11 & 1.72 & 227.29 & 2.36 & 103.50 & 3.75 & 166.25 & & & 5.29 & 110.03 \\
\hline Bar2 & 4.50 & 212.20 & 1.68 & 227.75 & 2.30 & 102.54 & 3.70 & 168.60 & & & 5.61 & 107.47 \\
\hline Ibiz & 1.70 & 216.61 & 0.58 & 240.71 & 2.22 & 107.47 & 3.70 & 166.56 & 5.26 & 282.59 & 1.94 & 255.91 \\
\hline Ibi2 & 1.77 & 215.69 & 0.69 & 231.21 & 2.19 & 104.41 & 3.83 & 168.17 & 7.64 & 289.38 & 2.21 & 253.83 \\
\hline Tene & 72.14 & 29.24 & 27.99 & 52.61 & 4.86 & 292.08 & 6.45 & 40.88 & 3.59 & 245.31 & 3.32 & 359.50 \\
\hline Ten2 & 70.68 & 28.61 & 27.23 & 52.52 & 4.77 & 292.16 & 6.17 & 39.62 & 2.84 & 247.83 & 3.15 & 0.62 \\
\hline LasP & 75.44 & 28.58 & 29.02 & 52.92 & 4.94 & 293.13 & 6.19 & 40.33 & 3.78 & 276.86 & 2.18 & 15.00 \\
\hline Las2 & 75.92 & 28.13 & 29.03 & 53.05 & 4.93 & 292.37 & 6.24 & 40.53 & 3.93 & 276.46 & 2.40 & 18.27 \\
\hline Fuer & 80.84 & 33.54 & 30.81 & 57.41 & 5.16 & 294.85 & 6.21 & 40.77 & 3.43 & 250.05 & 1.09 & 335.86 \\
\hline Fue2 & 80.81 & 32.32 & 30.61 & 56.26 & 5.17 & 293.82 & 6.13 & 39.21 & 3.92 & 247.06 & 1.30 & 333.50 \\
\hline Hier & 59.54 & 23.26 & 24.69 & 47.70 & 4.31 & 291.69 & 6.15 & 32.97 & & & 2.39 & 110.81 \\
\hline Hie2 & 59.86 & 21.31 & 24.71 & 45.47 & 4.24 & 290.71 & 6.05 & 32.56 & & & 2.51 & 109.27 \\
\hline
\end{tabular}

and especially for monthly means is much smaller than for 5 min and hourly values, so an individual wrong value will have a greater effect on the final statistics shown in these tables. The worst values are found for Huelva, Ibiza, Bilbao, Santander and Coruña stations, in all the cases related to a seasonal signal in the SRD (related to seasonal variations of the air-temperature effects in acoustic sensors) and AAND sensors (Ibiza case). Interestingly, some stations that presented important problems in the higher frequency and tidal analysis comparisons do not reveal large errors in these statistics. This is the case for Bonanza, for example.

Altimetry data have allowed a better determination of the impact on mean sea levels of problems that appeared in both the old and the new stations. For example, the delamination problem detected in many MIROS stations, most of the time after simultaneous operation with the old sensor, was clear and easy to correct during this exercise. Figure 11 shows this problem at Huelva station. The monthly means of the altimeter data obtained as explained in Sect. 3.2 are plotted against the monthly means from the two tide gauges at Huelva: the SRD sensor until 2008 and the MIROS sensor since 2008 (the three time series are constrained to have the same average value over their common period). A delamination problem started at the end of 2010, well after the comparison period between the two tide gauges, causing a permanent bias of $7 \mathrm{~cm}$ in the MIROS sensor. The problem disappeared when the antenna was replaced in mid 2011; once in the laboratory, the bias magnitude was confirmed to be related to a constant offset in the antenna. The plot shows the original time series constructed from the tide gauges in 
Table 9. Results obtained from the hourly residual time series. Stdv: standard deviation of the differences, $R_{\max }:$ maximum difference, $R_{\min }$ : minimum difference, $R$ : correlation coefficient). $a, b: y$ intercept and slope of the regression fit.

\begin{tabular}{lrrrrrrrr}
\hline St1/St2 & $\begin{array}{r}\text { Bias } \\
(\mathrm{cm})\end{array}$ & $\begin{array}{r}\text { Stdv } \\
(\mathrm{cm})\end{array}$ & $\begin{array}{r}R_{\max } \\
(\mathrm{cm})\end{array}$ & $\begin{array}{r}R_{\min } \\
(\mathrm{cm})\end{array}$ & & $b$ & $R$ \\
\hline Bilb/Bi13 & 0.01 & 1.83 & 8.60 & -7.70 & -0.01 & 0.9900 & 0.98 \\
Sant/San2 & 0.05 & 1.26 & 6.20 & -4.70 & -0.05 & 1.0268 & 0.99 \\
Gijo/Gij2 & 0.00 & 1.89 & 9.00 & -7.40 & 0.00 & 0.9739 & 0.98 \\
Coru/Cor2 & 0.04 & 1.02 & 7.70 & -4.60 & -0.04 & 1.0151 & 0.99 \\
Vill/Vil2 & 0.05 & 1.13 & 5.20 & -5.40 & -0.05 & 0.9943 & 0.99 \\
Vigo/Vig2 & 0.12 & 1.56 & 9.30 & -7.30 & -0.12 & 0.9940 & 0.99 \\
Huel/Hue5 & 0.03 & 1.43 & 6.10 & -5.40 & -0.03 & 1.0024 & 0.98 \\
Bona/Bon2 & 0.03 & 1.82 & 9.80 & -9.60 & -0.03 & 0.9778 & 0.99 \\
Mala/Mal3 & 0.03 & 1.19 & 3.40 & -6.50 & -0.03 & 1.0398 & 0.99 \\
Vale/Val3 & 0.16 & 1.05 & 7.00 & -2.50 & -0.16 & 0.9556 & 0.99 \\
Ibiz/Ibi2 & -0.13 & 1.05 & 3.30 & -5.00 & 0.13 & 1.0025 & 0.99 \\
Barc/Bar2 & 0.24 & 1.07 & 3.70 & -3.30 & -0.24 & 1.0271 & 0.99 \\
Tene/Ten2 & 0.01 & 1.35 & 9.90 & 9.80 & -0.01 & 0.9835 & 0.95 \\
LasP/Las2 & 0.06 & 1.04 & 8.00 & -6.90 & -0.06 & 0.9754 & 0.98 \\
Fuer/Fue2 & 0.06 & 0.82 & 3.00 & -7.80 & -0.06 & 0.9929 & 0.98 \\
Hier/Hie2 & 0.01 & 0.81 & 4.40 & -3.10 & -0.02 & 0.9908 & 0.99 \\
\hline
\end{tabular}

red, and the final time series in blue when the delamination bias was corrected. The trends (in $\mathrm{cm} \mathrm{yr}^{-1}$ ) correspond to the period 1992-2011 and are significantly affected by this correction (from 0.62 to $0.40 \mathrm{~cm} \mathrm{yr}^{-1}$ ), which in this case yields to a value closer to the altimetry trend. In the same way we have detected and corrected delamination problems in other stations like Barcelona, Gijón, Las Palmas or Vilagarcía.

Other times, the altimeter data helped to confirm a problem in the old sensor instead. This is the case of Ibiza. Figure 12 shows the comparison of monthly means from altimetry and from the tide gauge time series at this Mediterranean station, where the installation of the MIROS (data since October 2009) clearly results in a better agreement with the altimeter data. This is due to a problem in the seasonal cycle of the pressure sensor, already detected in other steps of the comparison.

Once all the stations were quality controlled in this way, the linear trends from altimetry and tide gauge monthly means for the same period of time were computed and are presented in Table 10. Although comparison of these two trends must be done carefully due to the differences explained in Sect. 3.2, monthly means from the tide gauges have been used in other works for this purpose (García et al., 2012 ). The glacial isostatic adjustment (GIA) is the only component of land movement at the tide gauges that we know from the Peltier model (Peltier, 2004). The impact of GIA in the relative sea level change at each tide gauge has been added to Table 10, where it can be seen that its value is generally one order of magnitude smaller than the errors in our trends, so its correction is not relevant in this study. On the other hand, Ibiza is the only station with a Continuous Global Positioning System sensor providing information
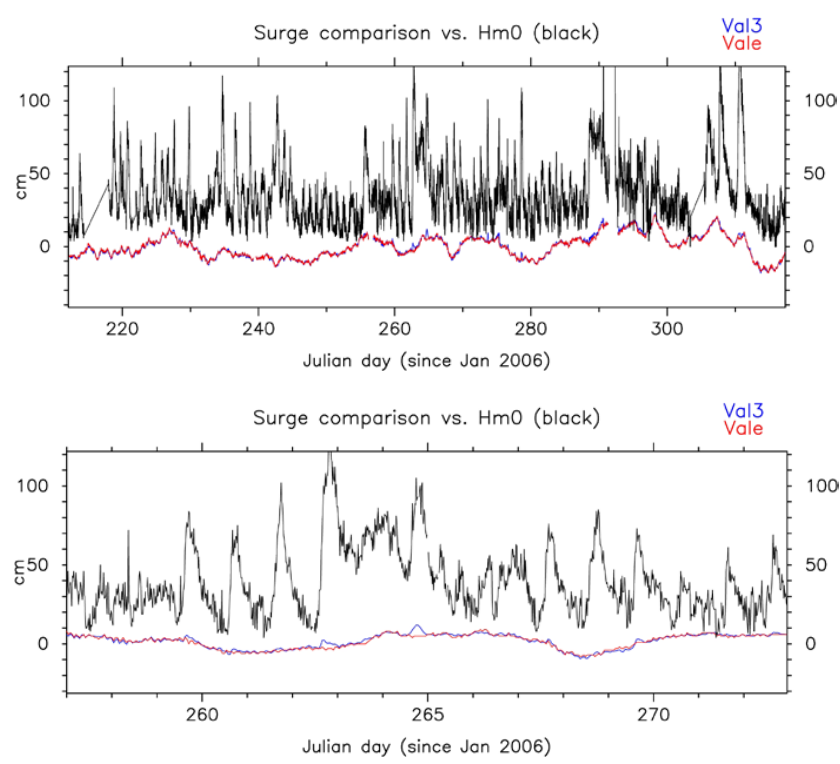

Fig. 10. Wind waves recorded by the MIROS sensor (black, Hm0) plotted with the hourly surge component (blue for the MIROS, red for the SRD) at Valencia harbour. Top: whole redundancy period, bottom: just September 2006. The new sensor is placed in an exposed area, the SRD in a rather closed dock and measuring inside a tube. There seems to be a small effect of higher waves in the MIROS surge component.

on the real local movement of the tide gauge (CGPS@TG) $\left(-0.113 \pm 0.02 \mathrm{~cm} \mathrm{yr}^{-1}\right.$, data available at the SONEL web page, Santamaría-Gómez et al., 2012), a significant subsidence that it is not enough, however, to explain the larger trend in the tide gauge. CGPS trends included in the table 
Table 10. Trends in $\mathrm{cm} \mathrm{yr}^{-1}$ obtained for the combined historical monthly means at each station without correcting the overlapping bias (4th column) and with correcting this bias (5th column). Altimeter trend for the same period, GIA component and GPS information, if available, have also been included. Rows written in bold show the stations where the bias significantly affects the computed sea level trend in the tide gauge; the * indicates for which stations the correction of the bias is recommended. An upward arrow in the last column indicates that the trend in the tide gauge is clearly larger than the one in the altimeter.

\begin{tabular}{|c|c|c|c|c|c|c|c|c|}
\hline Station & $N_{\text {years }}$ & $\begin{array}{l}\text { Bias overl. } \\
\text { period }(\mathrm{cm})\end{array}$ & $\begin{array}{l}\text { TG trend } \\
\left(\mathrm{cm} \mathrm{yr}^{-1}\right)\end{array}$ & $\begin{array}{l}\text { TG Trend with } \\
\text { Bias }\left(\mathrm{cm} \mathrm{yr}^{-1}\right)\end{array}$ & $\begin{array}{r}\text { Altimeter } \\
\text { trend }\left(\mathrm{cm} \mathrm{yr}^{-1}\right)\end{array}$ & $\begin{array}{r}\text { GIA } \\
\left(\mathrm{cm} \mathrm{yr}^{-1}\right)\end{array}$ & GPS & \\
\hline Bilbao* & 19.50 & 4.72 & $0.10 \pm 0.08$ & $0.26 \pm 0.08$ & $0.20 \pm 0.07$ & -0.015 & & $\uparrow$ \\
\hline Santander & 19.50 & -0.75 & $0.21 \pm 0.08$ & $0.17 \pm 0.08$ & $0.21 \pm 0.07$ & -0.011 & & \\
\hline Gijón* & 16.58 & -2.57 & $0.18 \pm 0.11$ & $0.08 \pm 0.11$ & $0.01 \pm 0.09$ & -0.004 & & $\uparrow$ \\
\hline Coruña* & 19.50 & -2.14 & $0.22 \pm 0.09$ & $0.13 \pm 0.09$ & $0.23 \pm 0.07$ & 0.0 & $-0.24 \pm 0.01$ & \\
\hline Vilagarcía* & 14.67 & 1.52 & $0.42 \pm 0.14$ & $0.53 \pm 0.14$ & $0.18 \pm 0.10$ & -0.008 & & $\uparrow$ \\
\hline Vigo & 19.17 & -0.71 & $0.26 \pm 0.10$ & $0.24 \pm 0.10$ & $0.25 \pm 0.06$ & -0.012 & $-0.05 \pm 0.26$ & $\uparrow$ \\
\hline Huelva & 15.25 & 0.23 & $0.40 \pm 0.11$ & $0.40 \pm 0.11$ & $0.35 \pm 0.09$ & -0.019 & $-0.19 \pm 0.5$ & $\uparrow$ \\
\hline Bonanza & 19.50 & 5.02 & $0.63 \pm 0.08$ & $0.77 \pm 0.09$ & $0.39 \pm 0.06$ & -0.019 & & $\uparrow$ \\
\hline Málaga & 19.50 & 0.18 & $0.47 \pm 0.07$ & $0.47 \pm 0.07$ & $0.38 \pm 0.08$ & -0.022 & & $\uparrow$ \\
\hline Motril & 7.00 & -3.06 & $0.40 \pm 0.31$ & $-0.20 \pm 0.31$ & $0.94 \pm 0.27$ & -0.020 & & $\uparrow$ \\
\hline Valencia & 19.17 & 9.67 & $0.75 \pm 0.10$ & $1.35 \pm 0.10$ & $\mathbf{0 . 3 8} \pm \mathbf{0 . 0 8}$ & -0.011 & $-\mathbf{0 . 0 8 1} \pm \mathbf{0 . 0 1 4}$ & $\uparrow$ \\
\hline Barcelona & 19.33 & -0.81 & $0.67 \pm 0.09$ & $0.64 \pm 0.09$ & $0.30 \pm 0.10$ & 0.003 & & $\uparrow$ \\
\hline Ibiza & 8.92 & 1.25 & $0.82 \pm 0.25$ & $0.98 \pm 0.25$ & $0.45 \pm 0.27$ & 0.014 & $-0.113 \pm 0.020$ & $\uparrow$ \\
\hline Tenerife* & 19.42 & 1.23 & $\mathbf{0 . 6 5} \pm \mathbf{0 . 0 7}$ & $0.69 \pm 0.07$ & $0.38 \pm 0.06$ & 0.008 & & $\uparrow$ \\
\hline Las Palmas & 19.50 & -0.01 & $0.60 \pm 0.05$ & $0.60 \pm 0.05$ & $0.36 \pm 0.05$ & 0.005 & $-0.156 \pm 0.034$ & $\uparrow$ \\
\hline Fuerteventura & 8.92 & 4.26 & $1.16 \pm 0.19$ & $1.58 \pm 0.19$ & $0.45 \pm 0.16$ & -0.001 & & 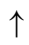 \\
\hline Hierro & 7.58 & -0.30 & $1.63 \pm 0.27$ & $1.58 \pm 0.27$ & $0.71 \pm 0.23$ & 0.009 & & $\uparrow$ \\
\hline
\end{tabular}

were obtained for other harbours also from SONEL, but these stations are not close nor collocated with the tide gauge so the values must be taken only as a reference: in Huelva the error of the trend is very large; in Coruña the subsidence itself is large $\left(-0.24 \mathrm{~cm} \mathrm{yr}^{-1}\right)$ and reflects a very local movement of the CGPS location (at another pier) not apparent in the tide gauge. The objective of Table 10 is to show the impact of correcting the overlapping period bias to the tide gauge time series; this correction is not needed, from the statistical point of view, if the bias is smaller than $1 \mathrm{~cm}$. This is the case for Santander, Vigo, Huelva, Málaga, Barcelona and Las Palmas. All these stations, except Huelva, have more than $19 \mathrm{yr}$ of data, the longest periods in the network, so the standard error of these trends is usually smaller. The correction is not significant in either Ibiza and Hierro, but in this case the error of the trend is larger because there are only 7 to $10 \mathrm{yr}$ of data (as in Motril). The bias correction is significant for the following stations: Bilbao, Gijón, Coruña, Vilagarcía, Bonanza, Motril, Valencia, Tenerife and Fuerteventura (bold formatted in the table). In summary, it seems that a bias equal to or larger than $1.5 \mathrm{~cm}$ may affect the trend for this length of time series (around $20 \mathrm{yr}$ ). The $4.7 \mathrm{~cm}$ bias in Bilbao may be related to an error in the datum definition of the SRD, which could account for half of this difference, combined with the influence of the large distance between the stations $(1 \mathrm{~km})$. Valencia bias is known to be originated by a problem in the SRD sensor that is probably related to an accidental change of datum during maintenance performed in
2003 rather than to harbour development, as has been stated in García et al. (2012). This error could explain at least 6 of the $9.67 \mathrm{~cm}$ of bias observed during the overlapping period. The rest could also reflect the large distance between the two tide gauges in Valencia $(2.5 \mathrm{~km})$ and also the very different wave and other environment conditions. Other stations with bias related to the old sensor are Bonanza (fresh water trapping in the SRD tube), Motril and Fuerteventura (wrong definition and inaccuracies of the pressure sensor) and Coruña, Gijón and Tenerife (clearly related to the scale error in the SRD).

The decision to apply this bias correction is not easy and clear-cut. It is not possible to know if the bias is due to a temporal problem in the old sensor affecting only the overlapping period, in which case the bias, although significant, should not be corrected, or if it is a constant bias due to the technology change. We think Bonanza, Motril and Fuerteventura could correspond to the first case; in fact the trends become less similar to the trends in the altimeter and other stations in the region if we apply the correction. However this bias may be needed in Bilbao, Gijón, Coruña and Tenerife.

\section{Conclusions}

A change of technology in a sea level network is a difficult and risky process that may introduce artificial effects in the final sea level products. This is particularly important if the 


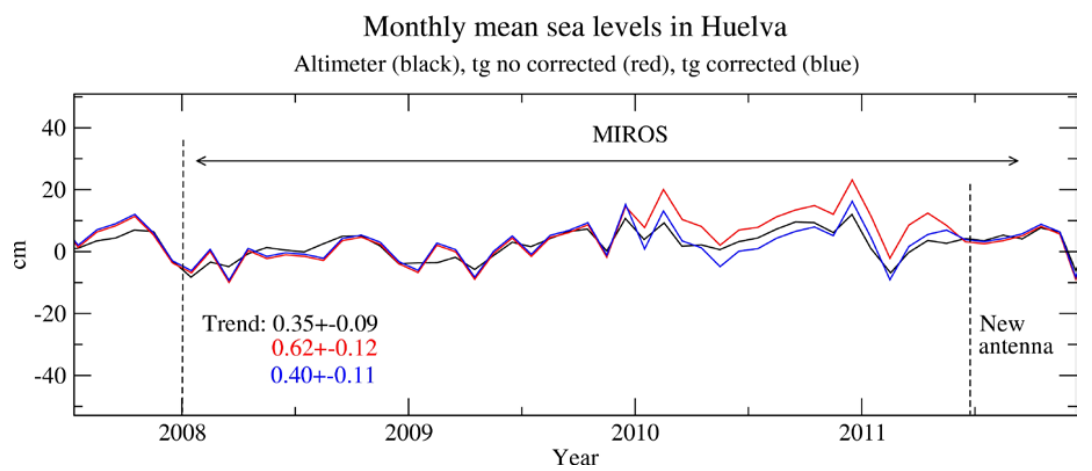

Fig. 11. Altimetry data (black line) helps to confirm the problem of delamination in the MIROS antenna at Huelva harbour. Monthly means at Huelva combining the SRD until 2008 and the original data from MIROS since then (red) show a problem in the radar since end of 2009 until the installation of a new antenna. Blue line corresponds to the corrected time series. Trends correspond to the period 1992-2011 for the three time series, in $\mathrm{cm} \mathrm{yr}^{-1}$. The trend changes significantly once the correction is made.

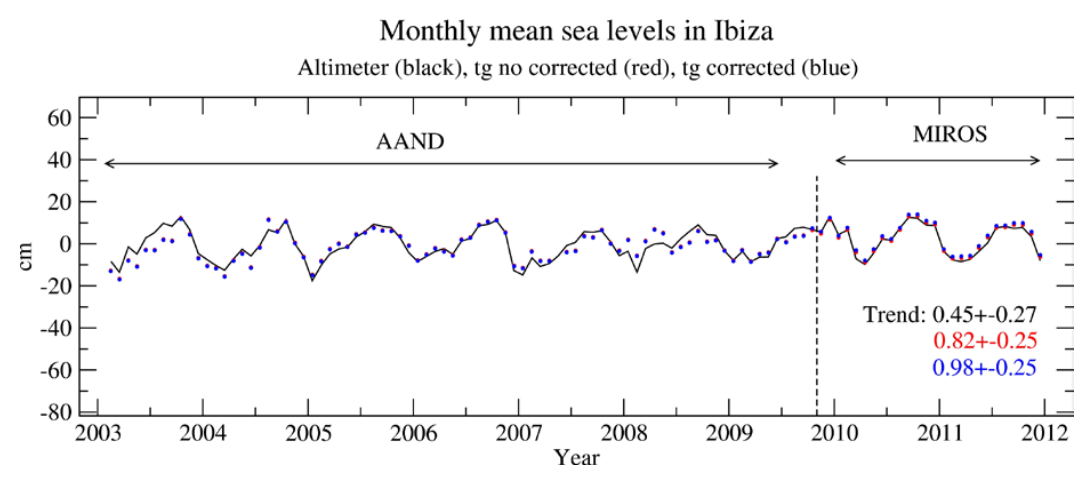

Fig. 12. Altimetry data (black line) vs. tide gauge monthly means at Ibiza station. The tide gauge time series are generated by combining the monthly means of the AAND sensor until September 2009 and the MIROS data since then. A seasonal signal is clear in the pressure sensor that disappears in the radar data, which shows a much better agreement with the altimetry. The bias from the comparison period (1.25 $\mathrm{cm})$ is relatively small and related to the problems in the AAND; its correction is not statistically significant for the trends (short time series and large error).

objective of the network is not just the operational applications but also the study of historical mean sea level changes

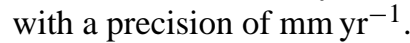

The REDMAR network renovation started with an experiment at the Vilagarcía pilot station in 2002-2003 and has been performed progressively during the last years by installing new sensors in the existing 17 stations and additionally 15 new stations around the Spanish coast. The equipment selected for the new stations is the MIROS CWFM radar sensor due to its good results in Vilagarcía experiment and its capability to provide simultaneous wave measurements. In order to quantify eventual differences due to the change of equipment, redundancy of operation has been ensured as far as possible in the old stations, following GLOSS recommendations.

The work has shown a diverse range of situations and sources of error when dealing with stations in different meteorological, oceanographic and environmental conditions. Intercomparisons of time series from 5 min to monthly means, tide and surge have shown insignificant differences and good performance in both old and new tide gauges for just 7 of the 17 upgraded stations. The rest of the stations present different problems, most of the time due to malfunction in the old sensor.

One of the main conclusions of the work is that most of the original acoustic SRD sensors of REDMAR presented a scale error that varies between $1 \%$ and $2 \%$ for the stations with larger tidal range, i.e. those located on the Spanish Atlantic coast, including the Canary Islands. This error, which reflects in a larger tidal range of between $1 \%$ and $2 \%$ for the old sensors, is responsible for a bias in the differences between time series during the overlapping period that is recommended to be considered for adjustment of the long-term mean sea level records as they may affect the determination of sea level trends. More detailed studies should be made on the influence of this error and its seasonal variations in extreme sea level analysis, for example. 
On the other hand, the appearance of a delamination problem in several antennas provided by MIROS during recent years has complicated the comparison process and could also influence the final sea level products. As its main effect in the data is reflected usually as a slow initial drift that becomes a constant, normally the error can be corrected. The problem was easily solved in some stations by a comparison with nearby daily and monthly means from other stations (for example, in Las Palmas). However, where several antennas on the same coast may be affected, or if there are not nearby tide gauges, a more careful and detailed study using altimetry data was undertaken to better derive mean sea levels during the last few years.

The study has also revealed the uncertainty associated with trends determination from tide gauge stations when the history of the station is not well known, and how changes in the technology and other malfunctions may change the datum of the station slightly and influence continuity of monthly means time series. Use of altimetry has shown to be useful in some cases, but only when the error is large enough due to the inherent differences in the signal measured by the tide gauge and the altimeter and the lack of knowledge of local movements in the harbours.

Acknowledgements. The authors thank all the personnel and field technicians from SIDMAR (maintenance company) and the personnel from the Harbour Authorities for their critical role in the process of renovation of the REDMAR network. They thank as well the MIROS company for making the extra efforts necessary to solve the delamination problem in the new radar sensors and for listening to the requirements of Puertos del Estado concerning data formats and software. Altimetry Sea Level Anomaly (SLA) and Dynamic Atmospheric Correction (DAC) gridded data correction have been provided by AVISO (http://www.aviso.oceanobs.com).

Edited by: N. Pinardi

Reviewed by: J. She and three anonymous referees

\section{References}

Alasset, P. J., Hébert, H., Maouche, S., Calbini, V., and Meghraoui, M.: The tsunami induced by the 2003 Zemmouri earthquake $(\mathrm{Mw}=6.9$, Algeria): modelling and results, Geophys. J. Int., 166, 213-226, 2006.

Alvarez Fanjul, E., Pérez, B., and Rodríguez, I.: A Storm Surge Forecasting System for Spanish Waters, Scientia Marina, 65, 145-154, 2001.

Alvarez-Gómez, J., Olabarrieta, M., González, M., Otero, L., Carreño, E., and Martínez-Solares, J. M.: The impact of Tsunamis on the Island of Majorca induced by North Algerian Seismic Sources, Turkish J. Earth Sci., 19, 367-383, 2010.

García, F., Vigo, M. I., García-García, D., and Sánchez-Reales, J. M.: Combination of Multisatellite Altimetry and Tide Gauge Data for Determining Vertical Crustal Movements along Northern Mediterranean Coast, Pure Appl. Geophys., 169, 1411-1423, doi:10.1007/s00024-011-0400-5, 2012.
IOC: Manual on sea-level measurement and interpretation, Volume I: Basic Procedures. Intergovernmental Oceanographic Commission, Manuals and Guides No. 14, IOC, Paris, 84 pp., 1985.

IOC: Manual on sea-level measurement and interpretation. Volume 3 - Reappraisals and recommendations as of the year 2000, Intergovernmental Oceanographic Commission Manuals and Guides No. 14. IOC, Paris, 47pp. (See IOC 1985 for Volume 1, 1994 for Volume 2 and 2006 for Volume 4), 2002.

IOC: Manual on sea-level measurement and interpretation, Volume 4 - An update to 2006, edited by: Aarup, T., Merrifield, M. , Pérez, B., Vassie, I., and Woodworth, P., Intergovernmental Oceanographic Commission Manuals and Guides No. 14. IOC, Paris, 80 pp., 2006.

Lennon, G. W.: The evaluation of tide-gauge performance through the Van de Casteele test, Cah. Oceanogr., 20, 867-877, 1968.

Lentz, S. J.: The Accuracy of Tide-Gauge Measurements at Subtidal Frequencies, J. Atmos. Ocean. Technol., 10, 238-245, 1993.

Le Traon, P.-Y. and Dibarboure, G.: Mesoscale mapping capabilities of multi-satellite altimeter missions, J. Atmos. Ocean. Technol., 16, 1208-1223, 1999.

Le Traon, P.-Y., Dibarboure, G., and Ducet, N.: Use of a HighResolution Model to Analyze the Mapping Capabilities of Multiple-Altimeter Missions, J. Atmos. Ocean. Technol., 19, 2077-2088, 2001.

Martín Míguez, B., Pérez Gómez, B., and Alvarez Fanjul, E.: The ESEAS-RI Sea Level Test Station: Reliability and Accuracy of Different Tide Gauges, Int. Hydrograph. Rev., 6, 44-53, 2005.

Martín Míguez, B., Testut, L., and Wöppelmann, G.: The Van de Casteele Test Revisited: An Efficient Approach to Tide Gauge Error Characterization. J. Atmos. Ocean. Technol., 25, 12381244, doi:10.1175/2007JTECHO554.1, 2008.

Pascual, A., Faugère, Y., Larnicol, G., and Le Traon, P. Y.: Improved description of the ocean mesoscale variability by combining four satellite altimeters, Geophys. Res. Lett., 33, L02611, doi:10.1029/2005GL024633, 2006.

Peltier, W. R.: Global Glacial Isostasy and the Surface of the IceAge Earth: The ICE-5G(VM2) model and GRACE, Ann. Rev. Earth. Planet. Sci., 32, 111-149, 2004.

Pérez, B. and López Maldonado, J. D.: Experience with Sonar Research and Development (SRD) Acoustic Gauges in Spain, in: New technical developments in sea and land level observing systems, Paris, France, 14-16 October 2003, IOC, 193, 4-8, 2003.

Pérez, B. and Rodríguez, I.: Red de Mareógrafos de Puertos del Estado, Proceso de datos de marea, Internal report, 57, 1994.

Pérez, B., Vela, J., and Alvarez-Fanjul, E.: A new concept of multipurpose sea level station: example of implementation in the REDMAR network. In: Proceedings of the Fifth International Conference on EuroGOOS, May 2008: Coastal to global operational oceanography: achievements and challenges, Exeter, 2008.

Santamaría-Gómez, A., Gravelle, M., Collilieux, X., Guichard, M., Martín Míguez, B., Tiphaneau, P., and Wöppelmann, G.: Mitigating the effects of vertical land motion in tide gauge records using a state-of-the-art GPS velocity field, Global Planet. Change, 9899, 6-17, 2012.

Shih, H. H. and Porter, D. L.: Error models for stilling well float type tide gauges, Oceans 1981 Conf. Rep., 2, 1118-1124, 1981.

UNESCO: Tsunami Early Warning and Mitigation System in the North Eastern Atlantic, the Mediterranean and Connected Seas, NEAMTWS, Implementation Plan (Third Session of the Inter- 
governmental Coordination Group for the Tsunami Early Warning and Mitigation System in the North Eastern Atlantic, the Mediterranean and Connected Seas, NEAMTWS), IOC Technical Series No. 73, English copy, available at: http://ioc3.unesco, org/neamtws/, 2007.

Vinogradov, S. V. and Ponte, R. M.: Low frequency variability in coastal sea level from tide gauges and altimetry, J. Geophys. Res., 116, C07006, doi:10.1029/2011JC007034, 2011.
Welch, P. D.: The Use of Fast Fourier Transform for the Estimation of Power Spectra: A Method Based on Time Averaging Over Short, Modified Periodograms, IEEE Transactions on Audio Electroacoustics, AU-15, 70-73, 1967.

Woodworth, P. L. and Player, R.: The permanent service for mean sea level: un update to the 21 st century, J. Coastal Res., 19, 287295, 2003.

Woodworth, P. L. and Smith, D. E.: A One Year Comparison of Radar and Bubbler Tide Gauges at Liverpool, Int. Hydrograph. Rev., 4, 2-9, 2003. 